Boston University School of Law

Scholarly Commons at Boston University School of Law

Faculty Scholarship

$9-2013$

\title{
Capital Income, Risky Investments, and Income and Cash-Flow Taxation
}

Theodore S. Sims

Boston Univeristy School of Law

Follow this and additional works at: https://scholarship.law.bu.edu/faculty_scholarship

Part of the Tax Law Commons

\section{Recommended Citation}

Theodore S. Sims, Capital Income, Risky Investments, and Income and Cash-Flow Taxation, in No. 12-45 Boston University School of Law, Law and Economics Research Paper Series (2013).

Available at: https://scholarship.law.bu.edu/faculty_scholarship/23

This Article is brought to you for free and open access by Scholarly Commons at Boston University School of Law. It has been accepted for inclusion in Faculty Scholarship by an authorized administrator of Scholarly Commons at Boston University School of Law. For more information, please contact lawlessa@bu.edu.

BOSTON UNIVERSITY 


\title{
BU School of Law
}

\section{CAPITAL INCOME, RISKY INVESTMENTS, AND INCOME AND CASH-FLOW TAXATION}

\author{
Boston University School of Law Working Paper No. 12-45
}

(August 31, 2012)

Revision of September 4, 2013

\section{Theodore S. Sims}

Boston University School of Law

This paper can be downloaded without charge at:

http://www.bu.edu/law/faculty/scholarship/workingpapers/2012.html 
Revision of September 4, 2013

(Initial Version April 22, 2008)

\title{
CAPITAL INCOME, RISKY INVESTMENTS, AND INCOME AND CASH-FLOW TAXATION
}

\author{
Theodore S. Sims*
}

It has become conventional wisdom, based partly on postulated portfolio adjustments by investors in risky assets, (1) to view an income tax as equivalent to a tax levied only on the risk free return to capital and as therefore equivalent to a wealth tax; and (2) to view the difference between an income tax and a cash-flow consumption tax as limited to tax on the risk free return. I show that the propositions (1) equating an income tax to a tax on the risk free return, and (2) distinguishing an income tax from a cash-flow tax only by tax on the risk free return, are distinct. Drawing on the literature on optimal responses to taxation by holders of risky assets I show also that the postulated adjustments on which the second of those propositions depends entail implausible assumptions about behavior under uncertainty, and that the foundation for that claim is to that extent unsound. This in turn suggests that claims that the differences between income and cash flow taxation are minor should be treated with caution.

* Professor of Law, Boston University (sims@bu.edu). Thanks to William D. Andrews, Daniel I. Halperin, and Alvin C. Warren, Jr., for detailed comments on several versions of this paper, and to Michael Graetz, Michael C. Harper, Reed Shuldiner, Jeff Strnad, David I. Walker, and participants in a seminar and a summer workshop at Harvard Law School for comments on an earlier version. Thanks also to Jeff Arbeit, James Gadwood, Patrick Jaing, Robert Guth, and David Brigleb, all of Boston University School of Law, for invaluable research assistance. 



\section{CAPITAL INCOME, RISKY INVESTMENTS, AND INCOME AND CASH-FLOW TAXATION}

\section{INTRODUCTION}

At the center of the debate about taxing income or consumption is the treatment of capital income. That has been so certainly since Mill, and has been the object of exceptionally intense academic attention in the United States during the last forty years. ${ }^{1}$ At least since the work of Andrews it has been taken as the distinguishing feature of a cash-flow consumption tax, as compared to an accretion-style income tax, that while both taxes fall on labor earnings the former effectively exempts capital income. ${ }^{2}$ But that basic proposition has been modified in important respects. Among the most prominent modifications is the insight, originating with Warren, that the difference may only be that an income tax taxes the riskless rate of return, rather than actual realized returns, as applied to an investor's entire portfolio, and in so doing functions much like a wealth $\operatorname{tax}^{3}$ Warren's insight has led others to assert, especially in light of what might be

1 See, e.g., John Stuart Mill, Principles of Political Economy Book 5, Ch. 2 (1848, Kitchener, Batoche Books, 2001); Nicholas Kaldor, An Expenditures Tax (1955); Irving Fisher and Herbert W. Fisher, Constructive Income Taxation (1942); William D. Andrews, A Cash-Flow or Consumption Type Personal Income Tax, 87 Harv. L. Rev. 1113, (1974) [hereinafter Andrews (1974)]; Alvin C. Warren, Jr., Fairness and a Consumption-Type or Cash Flow Personal Income Tax, 88 Harv. L. Rev. 931 (1975); William D. Andrews, Fairness and the Choice Between a Consumption-Type or Accretion-Type Personal Income Tax: A Reply to Professor Warren, 88 Harv. L. Rev. 947 (1975); U.S. Treasury, Blueprints for Basic Tax Reform (Washington, D.C., January 1977); The Structure and Reform of Direct Taxation (Report of a Commission Chaired by James E. Meade) (London, Institute for Firscal Studies, 1978); Michael J. Graetz, Implementing a Progressive Consumption Tax, 92 Harv. L. Rev. 1575 (1979). See also Mark Kelman, Time Preference and Tax Equity. 35 Stan. L. Rev. 649 (1983); Barbara Fried, Fairness and the Consumption Tax, 44 Stan. L. Rev. 961 (1992).

2 Andrews (1974), supra note 1, at 1123-28. The insight originated with E. Cary Brown, Business-Income Taxation and Investment Incentives, in Income, Employment and Public Policy: Essays in Honor of Alvin H. Hansen 300 (1948) [hereinafter cited as Brown]. See infra Part II. Under a "cash-flow" consumption tax the cost of all productive investments would be allowed as a deduction in the year made, while all withdrawals for consumption would be taxed, much as though the existing limits on contributions to (for example) an individual retirement account were eliminated. Andrews (1974), supra note 1, at 1149; see infra notes 11 and 65.

3 The basis for this claim was first identified by Alvin C. Warren, Jr., Would a Consumption Tax be Fairer than an Income Tax?, 89 Yale J.L. 1081, 1105-07 (1980) [hereinafter Warren I]. Warren expressly draws on work flowing from the study of taxation and risk by Evsey D. Domar \& Richard A. Musgrave, Proportional Income Taxation and Risk-Taking, 58 Q. J. Econ. 388 (1944), see infra note 19, surveyed in Part III, to whom the observation is sometimes attributed. E.g., Noel B. Cunningham, The Taxation of Capital Income and the Choice of Tax Base, 52 Tax L. Rev. 17, 29 \& n. 51 (1995); Deborah Schenk, Saving the Income Tax with a Wealth Tax, 53 Tax L. Rev. 423426 \& n. 12 (2000). But, as far as I have been able to determine, the insight that adjusting asset holdings under an income tax can produce a result equivalent to taxing just the riskless return originated with Warren I. See Alvin C. Warren, Jr., How Much Capital Income Taxed Under an Income Tax is Exempt Under a Cash-Flow Tax?, 52 Tax L. Rev. 1 (1996) [hereinafter Warren II]; see also Cunningham, op. cit., 52 Tax L. Rev. at 32-35; Louis Kaplow, Taxation and Risk-Taking: A General Equilibrium Perspective, 47 Nat'1 Tax J. 789 (1994) [hereinafter Kaplow (1994)]; Louis Kaplow, Taxation and Risk-Taking: A General Equilibrium Perspective, NBER Working Paper No. 3709 (1991) [hereinafter Kaplow (1991)]; Reed Shuldiner, Taxation of Risky Investments. 
viewed as the historically low U.S. risk free rate, that for all the attention the question has attracted the choice between accretion and cash-flow taxation may not matter very much. ${ }^{4}$

Warren initially developed his insight through the study of portfolio adjustments by investors in risky assets when subjected to income and consumption taxes. In a later survey with more elaborate analysis he argued that the insight was not confined to adjustments of the sort he originally studied, eventually concluding that taxation of the risk free return was a plausibly general distinguishing feature of an accretion-style tax. ${ }^{5}$ That view has since achieved relatively widespread acceptance among serious students of taxation. ${ }^{6}$ It is the view to which the present study is addressed. In what follows I suggest, contrary to the argument of Warren's more recent work and the literature it inspired, that his original finding is fragile. It holds for the sort of tax-induced adjustment to risk he studied, and, with appropriate modifications, for portfolios containing more assets than two. I argue, however, that Warren's original results otherwise do not generalize as he suggests, and that the foundation for the claim that imposing an income tax is generally tantamount to taxing the original portfolio on the risk free return is unsound.

To develop that argument I begin in Part I with an example that illustrates the difference between cash-flow and income taxation in the setting of a two-asset portfolio, and then vary it to illustrate Warren's original modification. (Wherever possible I use Warren's examples to facilitate a comparison of his analysis with the argument advanced here.) In Part II I lay out the elements

(unpublished, April 5, 2005); David Weisbach, The (Non)-Taxation of Risk, 58 Tax L. Rev. 1 (2004).

4 For an extended recent treatment of the issue, see Henry J. Aaron, Leonard E. Burman, \& C. Eugene Steurele (eds.), TAXING CAPITAL Income (2007); see, e.g., Joseph Bankman \& Thomas Griffith, Is The Debate Between an Income and a Consumption Tax a Debate About Risk? Does It Matter?, 47 Tax L. Rev. 377 (1992); David F. Bradford, What's In a Name? Income, Consumption, and the Sources of Tax Complexity, 75 N.C.L. Rev. 223, 224-25 (1998); William M. Gentry and R. Glenn Hubbard, Distributional Implications of Introducing BroadBased Consumption Tax, 11 Tax Policy and the Economy 1, 1-9 (J.M. Poterba, ed. 1997); David Weisbach, The (Non) Taxation of Risk, supra note 3, at 2-3, 18-23. See also Joseph Bankman \& Barbara H. Fried, Winners and Losers in the Shift to a Consumption Tax 86 Georgetown L. J. 586 (1998). See infra Part IV.

5 Warren II, supra note 3, at 9-11.

6 That is, it seems to have become part of "conventional wisdom" that an income tax is equivalent to a tax on the riskless return (Bradford, supra note 4, at 224-25 \& n. 5), irrespective of how investors actually respond, E.g., Gentry \& Hubbard, supra note 4, at 6-9; Shuldiner, supra note 3, at 15-16; Weisbach, supra note 3, at 21-23. See infra Part IV; authorities cited infra note 52. See also Kaplow (1994), supra note 3, at 792-93, whose conclusions are predicated on very specialized assumptions about government behavior. An important exception is Ethan Yale, The Cary Brown Theorem and the Income Taxation of Risk, (unpublished manuscript, May 1, 2005), who argues that investors generally will not respond to an income tax by exactly offsetting the effect of the tax on risk. See infra Part III. Larry Zelenak, The Sometimes-Taxation of Returns to Risk-Bearing Under a Progressive Income Tax, 59 S.M.U.L. Rev 879 (2006), seems to accept the basic premise under a proportional tax, but argues for taxing returns to risk under a graduated tax, especially when the risk-free rate is substantial. 
of the problem more abstractly, to provide a foundation for studying in detail the generalization offered in Warren's later work, which I take up in Part IV. Before doing so, however, I turn in Part III to what has become nearly pervasive in this literature, namely the assumption that adjusting asset holdings so as exactly to offset the impact of income taxation on risk is not merely something that economic actors can but what optimally they should (and therefore will) do. On careful inspection economic modelling of the problem does not warrant that pervasive assumption. The insight of Part III, and a central contribution of the paper, is that except in narrow circumstances -- either that the risk free interest rate is zero, or that the actor's risk tolerance, and hence her optimal holding of the risky asset, is fixed and independent of her wealth -- economic actors in fact do not optimally respond to an income tax on risk as the literature inspired by Warren has so persistently assumed. ${ }^{7}$ In Part IV I return to the broader claim that, irrespective of how investors actually do respond, an income tax is still equivalent to a tax on the riskless return. There I suggest that what Warren and others treat as a basis for comparing income and cash flow taxation is better understood as illustrating alternatives to conventional income taxation; and, when so understood, that Warren's original insight holds only when it is assumed that an investor has actually responded to an income tax by attempting to preserve in a taxable world the risk that characterized her original holdings in a world without tax. In the more general case, as suggested by Part III, the effect of an income tax will depend on how investors actually respond to the tax, which will vary with their tolerance for risk.

In Part V I offer some thoughts on the implications of the analysis for the study of the adoption of a cash flow consumption tax. I note, in particular, that it is a mistake to infer (as some apparently have) from Warren's basic insight that the quantitative impact of abandoning the income tax would be small. ${ }^{8}$ To the contrary, the effect Warren isolated is implicit. Even when investors respond to income taxation as the literature so commonly assumes, the after-tax outcomes appear as equivalent to exempting the excess of the risky over the riskless return in the original portfolio. They are actually achieved, however, by investing more heavily in higher

7 See infra Part III; text and notes at note 43-49.

8 E.g., Weisbach, supra note 3, at 21-23; see Bankman \& Griffith, supra note 4, at 397-98, 406; Bankman \& Fried, supra note 4, at 540-44; Cunningham, supra note 3, at 37. But see Liam Murphy \& Thomas Nagel, The Myth of Ownership: Taxes and Justice 117-19 (2002). Kaplow (1994), supra note 3, reaches the conclusion that the effects of a tax on capital income and an ex ante tax on wealth would be identical, but on the specialized assumption that in the latter case government investments in risky assets offset those that private actors forego. See infra Part V. 
risk/higher (pre-tax expected) return investments. Higher pre-tax expected returns beget higher expected nominal tax payments; and, in contrast with standard analyses of the effects of cash flow taxation, in this setting the higher nominal tax payments are not systematically deferred. Those phenomena are illustrated using a multi-period example in which I allow for variation in the income tax treatment used as a baseline for comparison; the basic insight appears robust to such variation. On the whole, Part V suggests that, taken at face value, Warren's insight implies, if anything, that the quantitative impact of abandoning the income tax might very well be larger, not smaller, than is commonly supposed.

\section{Portfolio Adjustments to Income and CASh Flow TAXation (WARREn I)}

Consider an investor who allocates $\$ 100$ equally between investments in a risky asset with an expected pre-tax return of 8 percent and a risk free asset with a pre-tax return of 2. Although the examples that follow are not explicit about the matter, the assumptions (following Warren) are such that the riskiness of $\$ 1$ invested in the former (as measured by its "standard deviation") is 6.93 percent; hence the $\$ 50$ invested in the risky asset has an expected return of $\$ 4$ and standard deviation of $\$ 3.46$. $^{9}$ In the absence of tax the expected value of the entire portfolio in

9 In Warren's example the risky asset yields 12 percent with probability 3/4, and negative 4 percent with probability 1/4; it has an expected return of 8 and a standard deviation of 6.9282 percent. (Nothing depends on the particular numbers that are used.) The risky asset is technically a "random variable." Its expected value (or "mean", often denoted by $\mu$ ) is the probability-weighted average of its possible values. Its "variance" (usually denoted $\sigma^{2}$ ) is the probability-weighted average of the squares of the deviations of its values from the mean; it measures the dispersion of the random variable about the mean, and is one measure of its "risk." The "standard deviation" $(\sigma)$ is the positive square root of the variance, and, although scaled differently, contains the same information; the two will be referred to more-or-less interchangeably in what follows. While much contemporary financial theory measures "risk" in terms of an asset's covariance with "the market," variance (and standard deviation), or some other measure of own risk, has consistently been used in the literature on the interaction of taxation and risk, and that approach is taken here. E.g., Domar \& Musgrave, supra note 3; J. E. Stiglitz, The Effects of Income, Wealth and Capital Gains Taxation on Risk-Taking, 83 Q. J. Econ. 263, 269 (1969).

For a random variable $\tilde{R}$, with mean $\mu$ and variance $\sigma^{2}$, the mean and variance of a numerical (or "scalar") multiple $\beta \tilde{R}(\beta \in \mathbb{R})$ of $\tilde{R}$ are given by $\beta \mu$ and $\beta^{2} \sigma^{2}$, respectively; the standard deviation of $\beta \tilde{R}$ is just $|\beta| \sigma$. E.g., Paul L. Meyer, Introductory Probability and Statistical ApPlications 128-29, 134-37 (2d ed. 1970). That is, the mean and standard deviation just scale up or down as the random variable itself is rescaled. Since, given a tax rate $t, 1-t$ is just a number, the after-tax expected return from $\tilde{\mathrm{R}}$ is just $(1-t)^{*} \mu$, and just as importantly, its aftertax standard deviation is $(1-t)^{*} \sigma$. For future reference it is worth reciting the (perhaps obvious) fact that adding a non-random (i.e., riskless) component to a portfolio containing a risky asset affects the mean but not the variance of the portfolio. So if a riskless asset with return $r$ is added to a portfolio already containing $\tilde{R}$ the expected return would be $r+\mu$, but the variance would still be $\sigma^{2}$ (and the standard deviation $\sigma$ ). Ibid.

Given these considerations little is lost in simplifying the exposition for now by using the expected return on the risky asset, in lieu of recomputing expected return (and standard deviation) for each after-tax illustration. Both expected return and standard deviation adjust in a linear fashion (as outlined above) to both tax and portfolio adjustments. The $\$ 50$ invested in the risky asset has a pre-tax expected return of $\$ 50 * 0.08=\$ 4$, and standard deviation $\$ 50 * 0.069282=\$ 3.4641$, while the $\$ 50$ invested in the riskless asset produces $\$ 50 * 0.02=\$ 1.00$ for sure. 
a year would be $\$ 105$ and its expected one-year return 5 percent.

\begin{tabular}{||rrrr||}
\hline \multicolumn{2}{|c|}{ EXAMPLE 0 } & & \\
& Riskless (2\%) & Risky (8\%) & Total \\
Investment (After-Tax) & $\$ 50.00$ & $\$ 50.00$ & $\$ 100.00$ \\
Pre-Tax Return & $\$ 1.00$ & $\$ 4.00$ & $\$ 5.00$ \\
Investment Plus Return After Tax & $\$ 51.00$ & $\$ 54.00$ & $\$ 105.00$ \\
\hline
\end{tabular}

Under a 30 percent income tax, with no adjustment to the portfolio composition, the expected return (and standard deviation) would decline by the tax rate, the former to 3.5 percent: ${ }^{10}$

\begin{tabular}{||rrrr||}
\hline \multicolumn{5}{|c||}{ EXAMPLE 1 } & & \\
Income Tax: No Portfolio Adjustment & Total \\
& Riskless (2\%) & Risky (8\%) & $\$ 100.00$ \\
Investment (After-Tax) & $\$ 50.00$ & $\$ 50.00$ & $\$ 5.00$ \\
Pre-Tax Return & $\$ 1.00$ & $\$ 4.00$ & $\$ 1.50$ \\
Tax & $\$ 0.30$ & $\$ 1.20$ & $\$ 3.50$ \\
After-Tax Return & $\$ 0.70$ & $\$ 2.80$ & $\$ 103.50$ \\
Investment Plus Return After Tax & $\$ 50.70$ & $\$ 52.80$ & \\
\hline
\end{tabular}

Under cash-flow taxation the cost of the investment could be currently deducted (or "expensed"), while the withdrawal plus any return would be taxed. If the taxpayer were to reinvest

\section{Compare infra note 10.}

Note, finally, that the initial division of the portfolio between the risky and risk-free assets implies that the investor is risk averse. If she were risk neutral she would be indifferent between certain and expected returns of 8 percent, and would invest entirely in the risky asset. See, e.g., Mas-Colell, Whinston \& Green, Microeconomic Theory, at 185 (1995). See infra Part III, text and note at note 43.

${ }^{10}$ In this and subsequent examples, following note 9 , the change in after-tax portfolio risk, as measured by the after-tax standard deviation of the holding of the risky asset, will be identical in percentage terms to the change in the after-tax return to that holding. That is, the percentage change in portfolio risk can effectively be read off the change in after-tax return to the risky asset. Using Example 1 to illustrate, the after-tax expected return (see below) declines by 30 percent from $\$ 5.00$ to $\$ 3.50$, so the standard deviation of the return to $\$ 50$ invested in the risky asset should decline to $0.7 * \$ 3.4641=\$ 2.4249$. That may be verified by direct calculation. The good outcome on the risky investment is $0.12 * \$ 50=\$ 6$, the bad outcome is $-0.04 * \$ 50=-\$ 2$, so the good pre-tax portfolio outcome -- taking into account the $\$ 1$ sure return on $\$ 50$ invested in the risk-free asset -- is $\$ 7$ and the bad outcome is $-\$ 1.00$, producing either $\$ 4.90(p=3 / 4)$ or $-\$ 0.70(p=1 / 4)$ after tax. The squared deviations from the $(\$ 3.50)$ mean are $(\$ 4.90-\$ 3.50)^{2}=\$ 1.96$ and $(-\$ 0.70-\$ 3.50)^{2}=\$ 17.64$. Weighted by their respective $(3 / 4,1 / 4)$ probabilities the squares of the after-tax deviations (the variance) sum to $\$ 5.88$, and the positive square root of the variance (the standard deviation) is $\$ 2.4249$. 
all the tax savings (at 30 percent) from the deduction she could invest a total of $\$ 142.86$, which (plausibly) we may assume that she still divides equally between the two investments ${ }^{11}$ :

\begin{tabular}{|c|c|c|c|}
\hline \multicolumn{4}{|c|}{$\begin{array}{c}\text { EXAMPLE } 2 \\
\text { Cash-Flow Tax: Portfolio Scaled Up }\end{array}$} \\
\hline & Riskless (2\%) & Risky (8\%) & Total \\
\hline Investment (Pre-Tax) & $\$ 71.43$ & $\$ 71.43$ & $\$ 142.86$ \\
\hline Pre-Tax Return & $\$ 1.43$ & $\$ 5.71$ & $\$ 7.14$ \\
\hline Tax on Return & $\$ 0.43$ & $\$ 1.71$ & $\$ 2.14$ \\
\hline After-tax return & $\$ 1.00$ & $\$ 4.00$ & $\$ 5.00$ \\
\hline Tax on Investment & $\$ 21.43$ & $\$ 21.43$ & $\$ 42.86$ \\
\hline Investment plus Return After-Tax & $\$ 51.00$ & $\$ 54.00$ & $\$ 105.00$ \\
\hline
\end{tabular}

Observe that in response to cash-flow taxation the investor has simply scaled up her investments in both the risky and riskless asset such that, after taxation on surrender, they are restored to their pre-tax values, illustrating that, even with every dollar eventually taxed, cash-flow taxation confers the equivalent of an exemption. Since, moreover, the after-tax expected return on the risky asset now equals its pre-tax return in the original portfolio, it follows that the after-tax portfolio risk, as measured by the after-tax standard deviation on the risky asset, is likewise the same. ${ }^{12}$

Assume now that the investor were to respond to an income tax by adjusting her investment in the risky asset just as she did under the cash-flow tax, increasing it to $\$ 71.43$. Under the income tax, however, the cost of the investment may not be deducted, so that the investor cannot (as she could under the cash-flow tax) finance the increase out of tax savings from making the investment. Her total portfolio thus remains fixed at $\$ 100$, and she must finance the increase by reducing her holding of the riskless asset to $\$ 28.57 .{ }^{13}$ Her portfolio returns now look like this:

11 Since the investment may be deducted, the taxpayer can restore herself after-tax to the status quo pre-tax by scaling up both holdings proportionately. The deduction for $\$ 50$ invested in each asset produces tax savings (at $30 \%$ ) of $\$ 15$, reinvestment of that $\$ 15$ produces tax savings of $\$ 4.50$ more, and so on, with the sum of all tax savings converging to $\$ 21.43$, so that a total of $\$ 71.43$ may be invested in each asset. The sum is more readily given by $\$ 50 / 0.70=\$ 71.43$, where 0.70 is $l-t$ for $t=0.30$. See infra Part II. If she was satisfied with the status quo ante it is at least plausible that she would avail herself of the chance to end up at the same place after-tax. See infra notes 21 and 24.

12 See supra note 10.

13 This conclusion is not altered by the possibility of borrowing. If the investor cannot borrow at the risk free rate the least costly way of financing the increased investment in the risky asset is by reducing her holding of the riskless asset; if she can borrow at the riskless rate the debt-service on the amount borrowed would exactly offset the return on a corresponding portion of her holding of the riskless asset and the effect would be the same as if she 


\begin{tabular}{||rrrr||}
\hline \hline \multicolumn{5}{|c||}{ EXAMPLE 3 } & & \\
Income Tax: Adjustment to Risky Investment & \\
& Riskless (2\%) & Risky (8\%) & Total \\
Investment (After-Tax) & $\$ 28.57$ & $\$ 71.43$ & $\$ 100.00$ \\
Pre-Tax Return & $\$ 0.57$ & $\$ 5.71$ & $\$ 6.28$ \\
Tax & $\$ 0.17$ & $\$ 1.71$ & $\$ 1.88$ \\
After-Tax Return & $\$ 0.40$ & $\$ 4.00$ & $\$ 4.40$ \\
Investment Plus Return After Tax & $\$ 28.97$ & $\$ 75.43$ & $\$ 104.40$ \\
\hline \hline
\end{tabular}

Observe that the $\$ 4.00$ after-tax (expected) return to the risky asset -- and hence its after-tax risk, as measured by its standard deviation -- is once again the same as that asset's pre-tax expected return (and risk) in the original portfolio (Example 0). The portfolio risk is therefore also unchanged. $^{14}$ But the after-tax portfolio return is smaller by $\$ 0.60$ than the return on either (a) the original portfolio in a no tax world or (b) the after-tax portfolio (after having first been scaled up) under a cash-flow tax. That difference is equal to the tax liability the investor would have incurred had she been taxed as though she had invested her $\$ 100$ entirely in the riskless asset, producing a return of $\$ 2.00$ and tax (at 30 percent) of $\$ 0.60$. Overall, however, her after-tax return is what she would have earned had she invested her portfolio according to her original allocation, producing an expected return of $\$ 5.00$, and then paid that $\$ 0.60$ in tax. In other words, the difference between a cash-flow tax, and an income tax when the investor rescales her investment in the risky asset to preserve her original portfolio risk after tax, is that under the latter the investor's return is as though from her original portfolio -- $\$ 5.00$-- reduced by tax at 30 percent on the riskless rate as though earned on the entire portfolio. That is Warren's insight in a nutshell.

One thing bears underscoring before we proceed. As we will note in Part III, the study of portfolio adjustments like those just illustrated have their genesis in efforts to understand the impact of taxation on the willingness of economic actors to take risks. The subsequent literature

had simply reduced that holding. See William A. Klein, Borrowing to Finance Tax-Favored Investments, 1962 Wis. L. Rev. 608; Theodore S. Sims, Debt, Accelerated Depreciation, and the Tale of a Teakettle: Tax Shelter Abuse Reconsidered, 42 UCLA L. Rev. 263 (1995). When the adjusted coefficient on the risky asset exceeds 1, the taxpayer must finance the increase by borrowing, but the value of her portfolio net of the borrowing is unchanged. See infra note 31.

14 See supra note 10. 
originating with Warren has a different preoccupation, and that is with characterizing the burden of taxation on economic actors, assuming they adjust as the economic modelling is read to suggest. Taken at face value the investor in Example 3 pays tax at the nominal statutory rate on her nominal income, and in nominal terms pays more tax (\$1.88) than in Example 1 (\$1.50). Warren's implicit premise, however, is that neither Example 1 nor (at least in isolation) Example 3 captures the true incidence of an income tax on the investor in either example. The methodological underpinning to Warren's insight, and the thread that connects virtually all subsequent study of this problem, is that the appropriate way to understand the impact on the investor in Example 0 , who (in our illustration) would have chosen a 50-50 portfolio in the absence of tax, is to compare the pre-tax return (and risk) of that portfolio not with its nominally taxed counterpart (Example 1), but with her after-tax posture after having responded to the anticipated effects of taxation by altering her portfolio's pre-tax composition (as illustrated for now by Example 3).

I argue in what follows that much of what has since been claimed in the literature stems from having lost sight of that basic methodological fact. What has developed in its stead is a preoccupation with the equivalence between the outcome in Example 3 and taxing the entire original portfolio as though it earned only the riskless return. ${ }^{15}$ Equivalence in that sense is something that in principle holds for any after (income) tax portfolio. What has been lost sight of is that Example 3 illustrates that the incidence of an income tax is the same as taxing the riskless return to the original 50-50 portfolio only for an actor who it is known (or at least assumed) would have chosen that portfolio in the absence of a (30 percent) tax. Abetted by the widespread but theoretically unwarranted belief that grossing up is what investors optimally do, those two propositions have become virtually equated in the literature; ${ }^{16}$ but, while related to one another, they are distinct. A central objective of this article (taken up at the end of Part II and then

15 That equivalence (among other things) is most systematically explored in Kaplow (1991) and Kaplow (1994), supra note 3. Kaplow studies the differential impact of alternatives to (or perhaps constituent elements of) a conventional income tax, as well as versions of a consumption tax, assuming that tax has already been imposed. As such it focusses on equivalences among different systems in equilibrium, but does not analyze the impact or incidence of imposing an income tax or a consumption tax (or any of their equivalents) to begin with. Consequently, although (subject to its stringent assumptions) it does assert that a consumption tax is equivalent to a wage tax, and that an income tax is equivalent to a wage tax plus a tax on the riskless return, it does not speak to the differential effects of income and cash-flow taxes generally, nor (though it can easily be read otherwise) does it claim that the difference between the two is tax on the riskless return. Those limitations on the work are most explicitly acknowledged in the working paper version (Kaplow 1991). The distinction between equivalence among tax systems, and the effects of imposing them, is critical to what follows. See infra Part IV.

16 See infra Parts III-IV. 
developed in Part IV) is to disentangle the two.

Although the argument is a ultimately more intricate, the central insight can be previewed in a straightforward way. While Example 3 could be taken as illustrating the consequence of one of many possible adjustments by the investor in Example 0 when confronted with an income tax, it typically has also been viewed as illustrating what in such circumstances the investor optimally ought to and therefore actually will do. That latter, however, implies that the investor exhibits "constant absolute aversion to risk", ${ }^{17}$ and will seek to replicate after tax the risk that she would have chosen in a world without tax. If, however, her risk tolerance is different she will adjust to taxation in some different way. If, for example, she exhibits decreasing absolute aversion to risk -- that is, she takes on more risk the wealthier she is -- she would then be expected to adjust to being made poorer by the tax by taking on less risk than she would have undertaken in its absence. She would hold less than $\$ 71.43$ of the risky asset, her (after-tax) risk compared to her original (50-50) portfolio would be reduced, her after-tax return would decline by more than $\$ 0.60$, and it could no longer be said, either quantitatively or conceptually, that the incidence of the income tax was equivalent to a tax on the riskless return. That, in a nutshell, is the key to the argument that will be developed in Parts III and IV. ${ }^{18}$

\section{The EsSENTIAL INTRICACIES OF THE PROBLEM}

To any reasonably serious student of tax policy over the past 30 years, the mechanism that gives rise to these insights will not be in any way new. It is routinely encountered by students in introductory tax. In a world with a proportional income tax, pre-tax income $(\mathrm{P})$ is reduced by the product of that income and the marginal tax rate, so that after tax income (A) is given by

$$
P-t P=P(1-t)=A,
$$

from which it follows that the pre-tax equivalent of an item of after-tax income is

$$
P=\frac{A}{1-t} .
$$

$\mathrm{P}$ is then just the enlarged, or scaled-up (or, in tax jargon, "grossed-up") equivalent of $\mathrm{A}$, in that it is the amount which, when taxed at rate $\mathrm{t}$, is reduced precisely to A:

$$
P(1-t)=\frac{A}{1-t}(1-t)=A \text {. }
$$

\footnotetext{
17 See infra note 43; text and notes at notes 47-49.

18 See, in particular, the example in Part IV at notes 82-84.
} 
That simple relationship has played a central role in developing some of the more basic insights into the properties of broad based taxes, including two that drive the examples in Part I. The first, based on work originating with Domar \& Musgrave, is that, with some assumptions, a proportional income tax need have no impact on investors' preferences over risk. ${ }^{19}$ For someone contemplating investment in a risky asset having a random return $\tilde{R}$ with expected (mean) return $\mu$, and variance $\sigma^{2}$ (and standard deviation $\sigma$ ), income tax at rate $t$ would reduce the mean and standard deviation of the return to $\mu(1-t)$ and $\sigma(1-t)$, respectively ${ }^{20}$. It follows that an investor who preferred the mean and variance of the original investment $\tilde{R}$ might in principle scale up her pre-tax investment to $\tilde{R} /(1-t)$, so that after tax at rate $t$ the return would be $(1-t) \tilde{R} /(1-t)=$ $\tilde{\mathrm{R}}$, with original mean $\mu$ and standard deviation $\sigma$. It is just such an adjustment that was made to the investment in the risky asset in both the second and third examples of Part I.

The second insight, due originally to E. Cary Brown and central to the debate about income versus consumption taxation, is just the expensing/exemption equivalence illustrated in Example 2 in Part I. ${ }^{21}$ There the investor responded by enlarging her entire investment to the pre-tax equivalent of what she would otherwise have invested after tax. ${ }^{22}$ And it was as the

19 See infra Part III. Domar \& Musgrave, supra note 3, at 411-14; James Tobin, Liquidity Preference as Behavior Towards Risk, 25 Rev. Econ. Stud. 65, 67, 80-81; Jan Mossin, Taxation and Risk-Taking: An Expected Utility Approach, 35 Economica 74 (1968); J.E. Stiglitz, The Effects of Income, Wealth and Capital Gains Taxation on Risk-Taking, 83 Q. J. Econ. 263, 269-74 (1969); Agmar Sandmo, The Effects of Taxation on Savings and RiskTaking, in 1 Handbook of Public Economics 265, 293-297 (1985); Agmar Sandmo, Portfolio Theory, Asset Demand and Taxation: Comparative Statics With Many Assets, 44 Rev. Econ. Stud. 369 (1977); Anthony Atkinson \& J.E. Stiglitz, Lectures on Public Economics, 99-107 (1980). This literature was both inspired by and preoccupied with the claim that income taxation would reduce risk-taking; the principal burden of the literature is to suggest that in general it will not. Domar \& Musgrave did not themselves actually claim that investors would respond to an income tax by replicating after-tax their original pre-tax risk; only that they would increase their pre-tax holdings of risky assets compared to a no-tax world, thereby increasing total (public and private) risk, which was the issue of interest to them. Domar \& Musgrave, op. cit; see infra note 42. The pure finding that investors might by a simple adjustment to their asset holdings avoid the effects of a proportional income tax on risk emerged from the work by Mossin, supra, at 75-76, and Stiglitz, supra, at 270-74. See infra text and notes at notes 43-44.

20 See supra notes 9-10.

21 Brown, supra note 2. The requisites for equivalence include full deductibility of losses, constant tax rates over time, and the ability to invest the tax savings from expensing at the same rate of return as the investment that was expensed. Graetz, Implementing a Progressive Consumption Tax, supra note 1, at 1598-1602. With the latter assumption the equivalence holds in the presence of compound returns. See infra note 24. Views differ on whether the equivalence of expensing and exemption depends on the assumption that investors actually gross up their investments under a cashflow tax. E.g. Fried, Fairness and the Consumption Tax, supra note 1, at 988-90; Warren I at 1103-05; Yale; supra note 6, at 36-45.] It is sometimes claimed that, because the two involve similar adjustments, it is inconsistent to argue that economic actors will scale up investments in response to a cash-flow tax but do not do so to offset the effects of an income tax on risk. E.g. Weisbach, supra note 3, at 7; Bankman \& Fried, supra note 4, at 543; but see Yale, supra note 6. I address that argument infra, text and note at note 70 .

22 This is equivalent to reinvesting all the tax savings from expensing, which would mean that, after taxes have 
result of having "grossed-up" her investments to their pre-tax counterparts that the investor realized after-tax returns that were equivalent to an exemption from tax.

Despite its simplicity and by now pervasive familiarity, for purposes of the discussion that follows it will be useful to examine in greater detail the mechanics of the expensing-exemption equivalence, by decomposing the outlay into the original investment and the enlargement attributable to the gross up. Corresponding to $\$ 1$ of original investment, the grossed up investment will be $\$ 1 /(1-t)$, which we can decompose into $\$ 1$ and

$$
\begin{aligned}
\frac{1}{1-t}-1 & =\frac{t}{1-t}, \text { so that } \\
\frac{1}{1-t} & =1+\frac{t}{1-t} .
\end{aligned}
$$

In a way of describing this that has gone out of fashion, the second term on the right -- the additional investment attributable to expensing -- can be viewed as an interest-free loan from the government for the duration of the investment. ${ }^{23}$ And when the entire investment is taxed on surrender, ignoring for the moment any returns, the amount left after tax is

$$
\left[1+\frac{t}{1-t}\right][1-t]=1-t+t=1
$$

The algebra is trivial, in the absence of returns the relationship is identical, and the intuition may in any event be clear; but its importance cannot be adequately underscored. When an investment is grossed up -- that is, enlarged by precisely $\mathrm{t} /(1-\mathrm{t})$-- the after-tax proceeds (after "repayment" through taxation of the resulting interest-free loan) of the enlargement of the investment exactly offset the tax on the original investment; it is precisely that that creates exemption equivalence; the relationship holds regardless of the size of -- for any scalar multiple of -- any investment; and it holds when we add in returns, including compound returns. But when we do that the relationship holds, exactly, only when the return on the amount of the gross-up is the same as that on the original investment, as was so across the portfolio in Example 2. ${ }^{24}$

\footnotetext{
been (as they would be) imposed on liquidation of the investment, and ignoring any return, she would have in hand what (in the absence of expensing) she originally could have invested after tax.

${ }^{23}$ E.g., Stanley Surrey, Pathways to Tax Reform, at ; Richard A. Musgrave, Clarifying Tax Reform, 70 Tax Notes 731,735 (1996).

24 The enlarged investment, taking into account compound interest for $\mathrm{n}$ periods at rate $\mathrm{r}$ and subsequent taxation at rate $t$ of the entire investment plus interest, yields
} 
What is more, even when the gross up earns the same return as the original investment, the effect is somewhat more complex when the gross-up of one investment comes at the cost of reducing another, as occurs generally under an income tax, as illustrated in Example 3. So, as a final preliminary, I specialize the insight to an algebraic representation of two investments, with differing mean returns (denoted $\mathrm{P}$ and $\mathrm{r}$ ), ${ }^{25}$ between which an investor is assumed to allocate her entire portfolio. That is, a fraction, $\alpha, 0 \leq \alpha \leq 1$, is allocated to $\tilde{R}$ and the balance $(1-\alpha)$ to $\mathrm{r}^{26}$ With no tax the one-period expected return on this portfolio is

$$
\begin{gathered}
\alpha(1+\mathrm{P})+(1-\alpha)(1+r)= \\
1+\alpha \mathrm{P}+(1-\alpha) r ;
\end{gathered}
$$

that is, the original investment plus a weighted combination of the expected returns. If, instead, each return were subject to income tax at rate $t$, the after-tax expected returns would be

$$
1+\alpha \mathrm{P}(1-t)+(1-\alpha) r(1-t) .
$$

Now consider the effect on the portfolio return of an increase in the allocation to $\tilde{R}$ to what I denote ${ }^{27} \alpha_{\mathrm{r}} \equiv \alpha /(1-\mathrm{t})$, rewritten in the more explicit form (from 1):

$$
\left[1+\frac{t}{1-t}\right](1+r)^{n}(1-t)=(1+r)^{n},
$$

the discrete time expression for compound interest at rate $r$ in the absence of tax. The equivalence does not hold if the two terms in brackets in the expression above earn different rates of return. There is a parallel literature on whether, since some investments produce "inframarginal" (or "supranormal") returns that cannot freely be rescaled, the return on the second term in the expression above will be the "normal" return to capital, in which event it follows that a cash-flow tax will appear to burden only the excess of the inframarginal over the normal return; whereas an income tax will fall on the entire return. See Warren II, at 4-6. From this it is argued that the difference between cash-flow and income taxation of both returns to risk and inframarginal returns is tax on the riskless return. E.g., Bankman \& Fried, supra note 4, at 542-43; Gentry \& Hubbard, supra note 4, at 6-9; Weisbach, supra note 3, at 19-21. Addressing that literature is beyond the scope of this project, though the relationship between those observations is not entirely obvious.

${ }^{25}$ In anticipation of the discussion that follows I assume that one investment is risky, taking the form of a random variable $\tilde{R}$ having an expected (mean) return $\mathrm{P}$ and finite variance $\sigma^{2}$; and, in a slight abuse of notation that should induce no confusion, I use $r$ to denote both a "risk-free" asset and its "safe" return.

${ }^{26}$ If the weights are required to be non-negative, borrowing or shorting is not allowed. Either way the essential property is that the coefficients add up to one. The argument here is similar to that in Shuldiner, supra note 3, at 13.

27 I introduce the notation $\alpha_{\mathrm{r}}$ here to reduce confusion in Part IV, where we look at adjustments to achieve several different objectives under two different income tax regimes. I will reserve the coefficient $\alpha$ for portfolios under a conventional income tax, and $\gamma$ for corresponding portfolios under a "risk-free return only" equivalent tax. I reserve subscripts to denote the effects of different adjustments, so that (to take the example above) $\alpha_{r}$ denotes an adjusted coefficient that under a conventional income tax has the effect of taxing only the risk-free return across the entire original portfolio, while $\gamma_{\mathrm{r}}$ would denote the corresponding coefficient under an explicitly "risk-free return only" system. For a comparison of the coefficients used here with those in Warren II, see infra note 66. 


$$
\alpha_{r} \tilde{R}=\frac{\alpha}{1-t} \tilde{R}=\left[\alpha+\frac{\alpha t}{1-t}\right] \tilde{R}
$$

Taxing that at rate $\mathrm{t}$ produces:

$$
\left[\alpha+\frac{\alpha t}{1-t}\right] \mathrm{P}(1-t)=\alpha \mathrm{P}(1-t)+\alpha \mathrm{P} t=\alpha \mathrm{P}
$$

so that, as with any other grossed up return, the after-tax return shows up as equal to the return on the original (i.e., pre-gross up) investment, but now unreduced by any tax.

Of equal interest is the impact on the balance of the portfolio. The allocation to $r$ must be reduced from $1-\alpha$ to $^{28}$

$$
1-\alpha_{r}=1-\left[\alpha+\frac{\alpha t}{1-t}\right]=(1-\alpha)-\frac{\alpha t}{1-t},
$$

or by the amount by which the allocation to $\tilde{R}$ was increased. What's the effect of that reallocation? The after-tax return on the reallocated investment is

$$
\begin{gathered}
{\left[(1-\alpha)-\frac{\alpha t}{1-t}\right] r(1-t)=} \\
(1-\alpha) r(1-t)-\alpha r t=(1-\alpha) r-r t,
\end{gathered}
$$

which likewise equals the pre-tax return to the original allocation to $r$, but now as though reduced by tax at rate $t$ on $r$, the latter being the return on the entire $(\$ 1)$ portfolio at the riskless rate.

The combined effects of these adjustments can be restated in a somewhat more general way. Suppose that a portfolio with an (expected) after-tax return of $1+\alpha \mathrm{P}(1-\mathrm{t})+(1-\alpha) \mathrm{r}(1-\mathrm{t})$ is adjusted by adding $\varepsilon$ to $\tilde{R}$ and subtracting $\varepsilon$ from $r$; then the after-tax return is

$$
\begin{gathered}
1+(\alpha+\epsilon) \mathrm{P}(1-t)+(1-\alpha-\epsilon) r(1-t) \\
=1+\alpha \mathrm{P}(1-t)+(1-\alpha) r(1-t)+\epsilon(\mathrm{P}-r)(1-t),
\end{gathered}
$$

where the new final term says that the allocation of $\varepsilon$ away from $r$ to $\tilde{R}$ has altered the (expected) after-tax portfolio return by the product of $\varepsilon$ and the after-tax difference between the two returns. $^{29}$ But if, as in the example under study,

28 When the coefficients are not required to be non-negative, $\alpha /(1-t)>1$ is feasible, in which event the investor's position in the risk free asset will be short, i.e., she will borrow. See infra note 31 .

29 When $\varepsilon=0$, the portfolio return reduces to just $\alpha \overline{\mathrm{R}}(1-\mathrm{t})+(1-\alpha) \mathrm{r}(1-\mathrm{t})$. 


$$
\begin{gathered}
\epsilon \equiv \frac{\alpha t}{1-t}, \text { then } \\
\epsilon(\mathrm{P}-r)(1-t)=\alpha t(\mathrm{P}-r) .
\end{gathered}
$$

What that says is that the after-tax portfolio return is (1) increased by an amount equal to the tax on $\alpha \mathrm{P}$, and (2) reduced by an amount equal to the tax on $\alpha \mathrm{r}$. That is, when the allocation to $\tilde{\mathrm{R}}$ is enlarged by $\alpha t /(1-t)$, it produces additional revenue after tax $(\alpha \mathrm{Pt})$ just sufficient to offset the tax due on the original investment $\alpha \mathrm{P}$. When the allocation to $\mathrm{r}$ is symmetrically reduced, it induces a corresponding reduction in the after-tax return ( $\alpha \mathrm{rt})$, creating the appearance of an increase in tax on the allocation to $r$ to $(1-\alpha) r t+\alpha r t=r t$. The net effect of the increased return -in an amount equal to the tax on the excess of the risky over the riskless return in the original portfolio -- appears to offset the tax on the original allocation to $\tilde{\mathrm{R}}(\alpha \mathrm{Pt})$, and to enlarge (by $\alpha \mathrm{rt}$ ) the tax on the original allocation to $r((1-\alpha) r)$ so that the latter appears to be taxed as though it had been earned on the entire portfolio. ${ }^{30}$ That is the crux of Warren's original observation.

Three additional things are worth noting. First, the baseline allocation $\alpha$ is arbitrary; so in any two-asset case, grossing up the allocation to one asset (by dividing it by (1-t)) and reducing the allocation to the other always produces an (expected) after-tax portfolio return equivalent to the return on the original portfolio, under a system that taxed the entire portfolio on the return to the other asset. Second, the result can be extended to a portfolio of $n$ assets having different returns. In the extreme, when the allocations to all but one asset are enlarged (to $\alpha_{\mathrm{i}} /(1-\mathrm{t})$, for all $i<n)$ the result is a natural generalization of the two-asset case: the after-tax portfolio outcome is as though the returns to all enlarged assets were exempt and the entire (original) portfolio had been taxed on the return to the remaining ("riskless") asset. If, however, some smaller subset of coefficients is grossed up the consequences are somewhat more complex. ${ }^{31}$

30 A similar account may be found in Shuldiner, supra note 3, at 14 . The adjustment is algebraically equivalent to setting the tax rate on $\tilde{\mathrm{R}}$ to 0 , and enlarging that on $\mathrm{r}$ to $\mathrm{t} /(1-\alpha)$. See infra note 31 .

31 These results are developed in separate work, summarized in part in the Appendix. The basic insights are these. When some holdings are grossed up and the remainder reduced pari passu, the entire portfolio is taxed on the weighted average of the returns to the latter, normalized so that it is as if that average return were earned on the entire portfolio. The outcome is algebraically equivalent to setting the tax rate on the grossed up holdings to zero, and enlarging the tax rates on the returns to the remaining assets so that they effectively spanned the entire portfolio. If the coefficient(s) on the grossed-up asset(s) collectively exceed 1, all other holdings are liquidated and the investor finances the gross-up by borrowing. That is the case central to the work of Cunningham, supra note 3, who argues that the entire portfolio is then treated as though it were taxed on the rate at which the taxpayer borrows. That case is actually more complex: the result emphasized by Cunningham is obtained only when (as Cunningham's example assumes) the original portfolio was invested entirely $(\alpha=1)$ in the risky asset. [ $\alpha<1$, 
Returning to the two-asset case, the final point is somewhat elusive but for present purposes crucially important. The relationship between grossing up the holding (Example 3) of the risky asset from that in the baseline portfolio (Example 0), and the appearance of transformed taxation of the baseline portfolio, is a relationship that runs both ways. The fact that conventional taxation of the grossed-up portfolio is equivalent to taxing just the riskless rate on the entirety of the original portfolio also means this: starting from any portfolio under a conventional income tax there is a transformed portfolio that would produce the same after-tax outcome under a system that actually taxed all portfolios as though they earned only the riskless return. ${ }^{32}$ That second proposition is intimately related to what is illustrated in Examples 0-3, but it is not the same proposition. The latter proceed from the insight that an investor's pre-tax preferences for both return and risk can be replicated under a cash flow tax, and then gross up the holding of the risky asset to study how closely the taxpayer can come to duplicating that outcome under an income tax. Equivalence to riskless return only taxation of the original portfolio is a way of characterizing the answer; and, to the extent one is prepared to believe that grossing up is what investors actually do, offers some insight into the difference between income and cash flow taxation.

The second proposition is the inverse, namely that conventional income taxation of any portfolio can in principle be replicated by a transformation of that portfolio actually taxed as though the entire (transformed) portfolio earned only the riskless return. The required transformation is just the inverse of grossing up: rescale the holding of the risky asset down. So if $\alpha$ is some arbitrarily chosen coefficient on the risky asset under a conventional income tax, the portfolio with that holding adjusted to $\gamma=\alpha^{*}(1-t)$ will achieve the same outcome under an explicitly "riskless return only" system of taxation. ${ }^{33}$ And that is so for any after-income tax portfolio,

produces $\alpha \mathrm{R}+(1-\alpha) \rho$ - t $\rho$ after tax; compare to cash-flow treatment of infra-marginal. Interpretation?]

32 See Kaplow (1994), supra note 3, at 792-93.

33 To take the handiest example, imagine that the chosen starting point was the portfolio in Example 3, and the question was whether there existed a portfolio that would produce the same outcome under a system that actually taxed every portfolio as though it earned only the riskless return. The answer is yes, and the requisite portfolio would be that of Example 1 -- the taxpayer's original portfolio -- in which the coefficient on the risky asset was given by $\$ 71.43 * 0.70=\$ 50$. Taxing that portfolio as though it earned only the riskless return produces tax of $0.30 * \$ 2.00=\$ 0.60$, and reducing the pre-tax return $(\$ 5)$ by $\$ 0.60$ yields the same after-tax outcome as in Example 3. Just such an alternative (with just such an adjustment, offset by a corresponding increase in government holdings of risky assets) was used in Kaplow's equilibrium analysis of risk-taking and taxation. Kaplow (1994) supra note 3, at 793. For another illustration, see Examples 6 and 6A infra, text at notes 82-84.

More generally if, starting with some allocation $\alpha$, we were to gross up the coefficient (to achieve the same after-tax level of risk, or indeed for any reason), the resulting coefficient will be $\alpha /(1-\mathrm{t})=\alpha_{\mathrm{r}}$ (see supra note 27), 
independently of any relevance it may have to the comparison of income and cash flow taxation, and, in particular, irrespective of whether the taxpayer in fact would have chosen $\gamma=\alpha^{*}(1-t)$ as the coefficient on the risky asset in a world without tax. If, in contrast, our starting point is some arbitrarily chosen portfolio in a world with no income tax, in response to the advent of which the investor were to adjust her holding of the risky asset, conventional taxation of a portfolio with the holding of the risky asset fully grossed-up -- and of only that portfolio -- will be equivalent to taxing the original portfolio as though it had earned only the riskless return. It is the latter comparison, with its entailed assumption that grossing up is what investors actually do, that may shed light on the differential effects of income and cash flow taxation.

The distinction is sufficiently important to warrant restating in a slightly different way. For any two-asset portfolio $(\alpha, 1-\alpha)$ the outcome under a conventional income tax can in principle be replicated by the transformed portfolio $(\gamma, 1-\gamma)$, actually taxed as though it earned only the riskless return. That proposition is about whether, with the requisite adjustment, an income tax is "equivalent" to a tax on the riskless return. From that alone, however, one cannot infer that the burden of an income tax on the original portfolio actually equals a tax on the riskless return. ${ }^{34}$ That turns on whether, faced with an income tax, the inverse of that adjustment is what the taxpayer actually would do. It is accurate when, and only when, it somehow is also known that an economic actor who chose $(\alpha, 1-\alpha)$ under a conventional income tax would have chosen the transformed portfolio $(\gamma, 1-\gamma)$ in a world without tax. If not, the claim that the incidence of an income tax is equivalent to a tax on the riskless return is incorrect.

I turn to those two propositions next. Much of the literature following Warren's initial observation takes as given that investors will in fact respond to an income tax by grossing up their holdings of risky assets. I address that premise in Part III, which reviews briefly what modelling actually predicts about what economic actors optimally do. In Part IV I consider the broader claim that an income tax is equivalent to a tax on the riskless return, irrespective of what investors actually do, and its relevance to the incidence of an income tax on risky returns, as well as to the

and that will produce the same outcome as taxing the entire original portfolio on the risk-free return. From that it follows that the coefficient that achieves an equivalent outcome under an explicitly "risk-free return only" tax as we get with $\alpha_{\mathrm{r}}$ under the conventional tax will be given by $\gamma_{\mathrm{r}}=\alpha_{\mathrm{r}}^{*}(1-\mathrm{t})=[\alpha /(1-\mathrm{t})]^{*}(1-\mathrm{t})=\alpha$, that is, the original portfolio allocation. That observation is used in contructing Examples $2 \mathrm{~A}$ and $3 \mathrm{~A}$ infra, preceding note 68.

34 A contrary argument, made by both Shuldiner and Weisbach, supra note 3 , is addressed infra, at notes 78 80. 
comparative properties of income and cash-flow taxation.

\section{OPtimal AdJUSTMENTS to InCOME TAXATION}

The belief that the optimal response to an income tax on risk is simply to gross up holdings of risky assets, so widely reflected in the legal literature, ${ }^{35}$ turns out to be an undue simplification of what economic modelling of the problem predicts. Recall that the objective of the literature originating with Domar \& Musgrave was to study the impact of income taxation on the demand for risky assets. The motivating insight of that work was that, with full deductibility of losses, the government through taxation participates in both gains and losses from risk, taking a fraction of the gains and absorbing a fraction of the losses. When it rescales (reduces) through taxation the investor's return and risk, ${ }^{36}$ it does so by effectively taking on for itself that share of the risky investment. So, even in Example 1, in which (compared to Example 0) the investor's private after-tax return and risk have been reduced by the tax, total (or social) risk -- including that portion assumed by the government through taxation -- is unchanged. ${ }^{37}$ But since, with full deductibility of losses, taxation reduces return and risk symmetrically, an investor can move towards restoring after-tax her original pre-tax private level of risk (and return) by increasing her pre-tax holding of the risky asset to offset the impact of taxation, instances of which are illustrated in Part I. Any such move will operate to increase total (social) risk, and it is that insight that has been of central interest to economics. ${ }^{38}$ Under a cash-flow tax, moreover, she can in principle recover her original private risk-return profile, as illustrated by Example 2. That she would do so is plausible, at least assuming she can freely rescale her investment in the risky asset. ${ }^{39}$

How an investor should best respond to an income tax is more complex, given that, as illustrated by Example 3, she cannot recover her original combination of risk and return. ${ }^{40}$ The early studies assume full deductibility of losses (though they explores alternatives). They also

35 See authorities cited supra notes 3-4. An exception is Yale, supra note 6, at 54-67 \& n. 107, who in a slightly different way has advanced several of the observations made below.

36 See supra notes 9-10.

37 The distinction between "private" and "total" (or "social") risk originated with Domar \& Musgrave, supra note 3, at 410. See also, e.g., Stiglitz, supra note 9, at 269; Atkinson \& Stiglitz, supra note 19, at 98.

38 See supra text and note at note 19.

39 See supra notes $11 \& 24$.

40 That is, to recover her pre-tax risk she must give up some return, as described in Parts I-II above. As more fully developed below, she actually has a choice, between giving up return or taking on more risk. See infra text and notes at notes 53-63. 
assumed that the return to the riskless asset was zero, an assumption that in context seemed innocuous, appropriate, or both. ${ }^{41}$ Even with those assumptions, however, Domar \& Musgrave never claimed that investors will respond to a proportional income tax by grossing up holdings of risky assets. To the contrary, while they do assert that investors would increase pre-tax holdings of risky assets, thereby increasing social risk, at several points they are at pains to emphasize that investors would not necessarily recover after tax their original pre-tax private risk. ${ }^{42} 0$

The prediction that the optimal response might simply be to gross up holdings of risky assets was obtained only after the problem was reformulated using the axiomatic expected utility framework pioneered by von Neumann \& Morgenstern roughly contemporaneously with Domar $\&$ Musgrave's original work. ${ }^{43}$ When recast in that fashion it is not necessary to model risk

41 In both Domar \& Musgrave and Tobin, supra note 19, the use of a zero interest rate was a byproduct of the assumption that the riskless asset was cash. That assumption was required by the project in Tobin, whose objective was to explain "liquidity preference," that is, the willingness to hold (non-interest bearing) cash. In the context of Domar \& Musgrave's more general and path-breaking study the simplifying assumption seems innocuous enough.

42 Domar \& Musgrave, supra note 3, at 390, 411-14. At 414 they observe that in "the general case, it cannot be said whether any given tax will cause the investor to stop short of or exceed the private risk taken prior to the imposition of the tax", adding that from "the point of view of the economy, the question . . . is relatively unimportant. What matters is the degree of total risk taken jointly by the investor and the Government." The other important early study, Tobin, supra note 19 , at 80-81, which is preoccupied with accounting for liquidity preference and deals with taxation "in passing", contains an illustration suggesting that investors would respond to a 50 percent tax by doubling their holding of risky assets, but does not otherwise pursue the issue. Tobin represented the investor's preferences by quadratic utility, which is known to exhibit increasing absolute aversion to risk, and is for that reason generally regarded by economists as implausible, implying as it does that risky assets are "inferior" goods. See infra notes 43 and 53, Hence the implication of Tobin's example had to be an artifact of his assumption of a zero riskless return. See infra text at note 45 . The pre-expected utility approach of Domar \& Musgrave, which used loss aversion rather than the variance of a random variable as the measure of risk, has recently been resurrected by John Brooks, Taxation, Risk and Portfolio Choice: The Treatment of Returns to Risk Under a Normative Income Tax, 67 Tax L. Rev. 255 (1913). who like Domar \& Musgrave concludes that taxpayers would not fully gross up.

43 von Neumann \& Morgenstern, The Theory of Games and Economic Behaviour (1944). Domar \& Musgrave, supra note 3, at 395-97, took as their measure of risk the probability of negative returns; while Tobin, supra note 19, used a mean-variance approach to risk. The "expected utility" hypothesis -- that is, that economic actors might rationally maximize the expectation of some function of a random variable rather than simply its expected value -- was originally formulated by Daniel Bernoulli as a way of resolving the "St. Petersburg paradox." Daniel Bernoulli, Exposition of a New Theory on the Measurement of Risk, 22 Econometrica 23 (1954). von Neumann \& Morgenstern's axiomatic reformulation of expected utility is what led to its pervasive analytic use in addressing uncertainty.

The basic insight of the vNM formulation is that, subject to the requisite axioms, an individual's preferences over uncertain prospects consisting of lotteries on a space of outcomes can be represented by a utility function for money with the property that the value assigned to each lottery consists of the lottery (i.e., probability)-weighted values of the utilities of the constituent outcomes. That is, the expected utility of a given lottery is simply the expectation of the utilities of the outcomes. See, e.g., Mas-Colell, Whinston \& Green, Microeconomic Theory, supra note 9 , at $168-80$.

In an expected utility framework an actor's preferences towards risk are reflected in the shape of their utility 
explicitly; the actor's attitude towards risk is captured by the utility function for money that she is taken to maximize. As so recast the basic finding is indeed both simple and striking. With no restrictions on the probability distribution of the risky asset, or on the preferences represented by the investor's utility function other than that she be risk averse, the expected utility framework yields the insight that her optimal response to an income tax on returns to risk is simply to gross up her investment in the risky asset, just as the legal literature so widely assumes. ${ }^{44}$ It is perhaps by force of its striking simplicity that this finding has so influenced discussions of the issue ever since.

It is nevertheless subject to an important qualification. It turns out to depend almost entirely on the assumption that the riskless rate of return is zero. When that assumption is relaxed, income taxation will have the effect of reducing the investor's wealth, which, depending on the particulars of her tolerance for risk, may induce a change in her optimal holding of the

function (U) for money: risk aversion is captured by a function that is increasing $\left(\mathrm{U}^{\prime}>0\right)$ and strictly concave ( $\mathrm{U}^{\prime \prime}$ $<0)$. One who is strictly risk-averse (to any extent) prefers the utility from the expected value of a lottery (see supra note 9) to the expected utility of the lottery; and, by a proposition known as Jensen's inequality, that is a property of all increasing strictly concave functions. Id. at 183-89.

The degree of risk-aversion depends on the particulars of the curvature of the utility function, as captured by two measures due to Arrow, Aspects of the Theory of Risk-Bearing 28-44 (1965), and Pratt, Risk Aversion in the Small and in the Large, 32 Econometrica 122 (1964). Corresponding to a given money utility function U(x), where $\mathrm{x}$ denotes some monetary measure (such as wealth or income), the "coefficient of absolute risk aversion" (A) is defined by $\mathrm{A}(\mathrm{x})=-\mathrm{U}^{\prime \prime}(\mathrm{x}) / \mathrm{U}^{\prime}(\mathrm{x})$, and the "coefficient of relative risk aversion" by $\mathrm{R}(\mathrm{x})=-\mathrm{x} \mathrm{U}^{\prime \prime}(\mathrm{x}) / \mathrm{U}^{\prime}(\mathrm{x})$. An actor who exhibits constant absolute risk aversion holds some constant amount of a risky asset irrespective of her wealth (and will invest all her resources in the risky asset up to that amount and none thereafter). See, e.g., Atkinson \& Stiglitz, supra note 19, at 103 \& Figure 4-2(d). One who exhibits constant relative risk aversion invests some constant fraction of her assets in the risky asset irrespective of her wealth. Id. Figure 4-2(a).

Arrow conjectured that $\mathrm{A}(\mathrm{x})$ was plausibly decreasing and $\mathrm{R}(\mathrm{x})$ (modestly) increasing, that is, that individuals' holdings of risky assets increase with wealth, but less than proportionately. Arrow, op.cit., at 35; see also MasColell, Whinston \& Green, op. cit., at 191-94. Such conjectures remain subject to debate. E.g., Stiglitz, Review: Aspects of the Theory of Risk Bearing, 37 Econometrica 742 (1969). For recent conjectures about the value of the coefficient of relative risk aversion in the context of a highly entertaining review, see Martin L. Weitzman, Review of the Stern Review on the Economics of Climate Change, 45 J. Econ. Lit. 703 (2007). Economists are inclined to view increasing absolute risk aversion as unpalatable, as it implies that risky assets are "inferior" (i.e., their consumption declines with income), e.g., Arrow, op.cit; though one might question the reflexive application to preferences over risk of a taxonomy devised to explain preferences over consumption bundles. At a practical level a passing acquaintance with the debt-heavy composition of trusts administered for the benefit of wealthy Bostonians in the early 20th century, or of the tax-exempt debt-heavy portfolios of wealthy Florida retirees toward the end of that century, would caution against too preemptively dismissing increasing absolute aversion to risk (and, in the latter case, taxes) as a plausible account of reality.

44 The pathbreaking work was that of Mossin, supra note 19, at 75-77, and Stiglitz, supra note 9 at 271-74; see also the surveys in Sandmo, supra note 19, at 293-98; Atkinson \& Stiglitz, supra note 19, at 99-108; James M. Poterba, Taxation, Risk-Taking, and Household Portfolio Behavior, 3 Handbook of Public Economics 1109 (2002). The accounts in Mossin and Sandmo are in general more accessible, while the results in Stiglitz and Atkinson \& Stiglitz are more detailed. In the interest of simplicity the discussion in text generally follows the former. 
risky asset. With a non-zero interest rate, the tax-induced change in the optimal holding $(\partial \alpha / \partial t)$ is not simply $\alpha /(1-t)$, but is given by

$$
\frac{\partial \alpha}{\partial t}=\frac{\alpha}{1-t}-\frac{r W}{1+r(1-t)} \frac{\partial \alpha}{\partial W}
$$

where (as in Part II) $\alpha$ is the original pre-tax holding of the risky asset, $\mathrm{W}$ is wealth, and $\partial \alpha / \partial \mathrm{W}$ is the wealth derivative of the risky asset -- that is, the rate at which the holding of the risky asset changes with changes in wealth. ${ }^{45}$ From that expression it is clear that the second term will be zero, and the optimal holding of the risky asset will be exactly the grossed up holding $\alpha /(1-t)$, if either (a) the risk free rate is zero or (b) the wealth derivative of the risky asset is zero. ${ }^{46}$ In other words, except when the risk free rate is zero, the optimal holding may be altered by a taxinduced change in the investor's wealth.

The way in which the optimal holding of the risky asset changes with wealth will depend on the shape of the investor's utility function, as captured by the measures of absolute and relative risk aversion it induces. While the details of that relationship are intricate, ${ }^{47}$ the aspect of immediate relevance to the present discussion is not. The condition $\partial \alpha / \partial \mathrm{W}=0$ is that the optimal holding of the risky asset does not change with wealth, that is, that the investor exhibits constant absolute aversion to risk. ${ }^{48}$ An actor with such preferences will invest entirely in the risky asset up to some point, and will then invest everything thereafter in the riskless asset. ${ }^{49}$ Faced with

45 As previously noted this form of the solution follows Mossin, supra note 19, at 77 (equation 10); see also Sandmo, supra note 19, at 296. While the formal solution in both Stiglitz, supra note 19, and Atkinson \& Stiglitz, supra note 19, at 106 (equation 4.10), appears to differ from that in Mossin and Sandmo, it can be shown that equation (4.10) in Atkinson \& Stiglitz has the same form as equation (10) in Mossin, differing only by reason of differences in the way in which they formulate the investor's budget constraint. See also Shuldiner, supra note 3, at 15-16. The partial differential equation in the text is for the derivative of the optimal $\alpha$ with respect to the tax rate; the optimal holding itself is obtained by solving that equation. When the interest rate is zero and the solution contains only the first term, the optimal holding may be obtained by integrating both sides. See, e.g., Mossin, op. cit.

46 Sandmo, supra note 19, at 295-96, shows also that a simple gross-up is optimal for a non-zero interest rate if only the excess return to the risky asset $(\alpha(\tilde{R}-r))$ is taxed, that is, the tax rate on the riskless rate is zero. These aspects of the economic literature have not been widely appreciated, as emphasized by Yale, supra note 6, at 55-61. Weisbach, supra note 3, at 18, on the other hand, argues that wealth effects may be ignored, an argument I address in Part IV. See infra note 80.

47 They are explored in detail in both Stiglitz, supra note 9, at 271-274, and Atkinson \& Stiglitz, supra note 19, at 105-08; see also Mossin, supra note 19, at 77-78, 80-81.

48 See supra note 43. E.g., Mossin, supra note 19, at 81; Atkinson \& Stiglitz, supra note 19, at 102-06; Stiglitz, supra note 9, at 274.

49 See Atkinson \& Stiglitz, supra note 19, at 100-03 \& Ex. 4-2 and Fig. 4-2(d). If $r>0$ and $\partial \alpha / \partial W>0$ (decreasing absolute aversion to risk) the investor's optimal adjustment will be to something less than $\alpha /(1-t)$, and 
an income tax such an investor will be preoccupied foremost with restoring after tax her original pre-tax level of risk, which she can accomplish simply by grossing up. With any different risk tolerance, however, that will not be her optimal response.

In short, the belief that investors optimally should, or actually will, adjust to income taxation by grossing up holdings of risky assets requires either (a) that the riskless rate (or tax on that rate) be zero, or (b) that investors systematically exhibit constant absolute aversion to risk. The plausibility of that belief thus turns on the plausibility of those two conditions. While deployed by some in advocating the shift to a consumption tax, the assumption of a zero rate on short-term Treasury obligations is not generally consistent with the evidence. ${ }^{50}$ Constant absolute aversion to risk -- which implies that holdings of risky assets do not rise with wealth -- is viewed as neither an especially plausible hypothesis about attitudes towards risk nor consistent with available data. $^{51}$ If, as is generally regarded as more plausible, absolute aversion to risk is decreasing

conversely where $\partial \alpha / \partial \mathrm{W}<0$. See Stiglitz, supra note 9, at 272-274 \& Table I; Mossin, supra note 19, at 81 . See infra, Examples 4 and 6, text and notes at notes 53-57 and 82-84.

50 According to Ibbotson Associates, the nominal rate on U.S. Treasury bills averaged about 3.9 percent between 1926-2000. During the same period inflation averaged about 3.2 percent, and the average real return on Tbills was about 0.8 percent. Under an unindexed income tax what is taxed to an investor who fully grosses up will be the nominal rather than the real rate of interest. But even the real rate has not on average been zero, and there are periods in which it is substantial. In 2006, for example, the rate on Treasury bills averaged over 4.7 percent, while the inflation rate was under 2.1 percent, so that the real rate was over 2.5 percent. [Check Ibbotson data; Zelenak use of TIPS]. It is to be noted, moreover, that these are interest rates on short-term U.S. government securities, essentially cash. Long-horizon estimates of the real interest rate on medium- and long-term U.S. government securities tend to fall into the 2.7-3 percent range. See James A. Girola, The Long-Term Real Interest Rate for Social Securitu, U.S. Treasury Research Paper No. 2005-02 (March 30, 2005), and studies there cited.

Using similar data Bankman \& Griffith, supra note 4, argue that, as the impact of an income tax on risk could be eliminated by a gross-up, and the (real) riskless return was low, the import of choosing to tax consumption rather than income may be of less significance than is commonly believed. See also Weisbach, supra note 3, at 2325. [Check.] Ironically, Bankman \& Griffith's central illustration involves an investor with preferences characterized by logarithmic utility in an environment with a zero interest rate. But log utility belongs to the class of "constant relative risk aversion" (or "CRRA") utility functions, having a coefficient of relative risk aversion of 1. E.g., Mas-Colell, Whinston \& Green, supra note 9, at 194, 211 \& exercise 6.C.12; Arrow, supra note 43, at 37. An actor with such preferences exhibits decreasing absolute risk aversion. So the optimality of grossing up in their example (which Bankman \& Griffith appear to assume) is an artifact of their assumption of a zero interest rate, as illustrated by Yale, supra note 6, at 58-64, who uses log utility and a positive interest rate in a counter-example showing that grossing up is not always optimal.

51 As previously noted, Arrow's conjecture is that absolute aversion to risk is decreasing, so that holdings of risky assets rise with wealth; while relative aversion to risk is increasing, so that the fraction of the portfolio in risky assets declines with increasing wealth. Arrow, supra note 43, at 35. The hypothesis that absolute aversion to risk is decreasing rather than constant seems consistent with cross-sectional data on asset holdings. See, e.g., Stiglitz, supra note 9, at 267-268 \& n. 2; Stiglitz, supra note 43. There is also evidence consistent with the hypothesis of constant relative risk aversion, which implies decreasing absolute risk aversion. E.g., Pierre-Andre Chiaporri \& Monica Paella, "Relative Risk Aversion is Constant: Evidence from Panel Data," DES Discussion Paper No. 5 (University of Naples "Parthenope", 2008); see Raj Chetty, "A New Method of Estimating Risk 
rather than constant, then the wealth derivative of the risky asset in the expression above is positive, and the investor's optimal response to being made poorer by an income tax will be to adjust her holdings, but by something less than fully grossing them up.

\section{INCOME TAXATION AND CAPITAL INCOME (WARREN II, RECONSIDERED)}

The literature following Warren's original insight generally falls into one of two categories. Some simply overlook the qualification just described, taking as true that investors can and will gross up holdings of risky assets in response to an income tax, and proceeding from there to analyze either the comparative properties of income and cash-flow taxes or the shortcomings of the income tax. ${ }^{52}$ Others, however, go on to argue that, compared to a cash-flow tax, an income tax is equivalent to taxing only the riskless return, irrespective of how investors actually respond to its imposition. I take up the latter claims here. As previewed at the end of Part II, I argue that, in comparing the impact on risky investments of income and cash-flow taxation, the key inquiry is not whether an income tax is in some sense "equivalent" to a tax explicitly confined to the riskless return, as the literature has largely come to maintain. For comparative purposes what is crucial is the differential effect of either tax, as measured at least in principle from some common starting point. That, I argue, does turn on the particulars of how investors respond.

Under a cash flow tax, as illustrated by Example 2, the investor can in principle replicate her pre-tax risk-return profile. What remains to be considered is the import of different responses to an income tax, something that is more systematically addressed in Warren's later work. There he proceeded by exploring (among other things) the effects of other possible portfolio adjustments. Suppose, he asked, the investor reallocated her portfolio not to replicate after tax her original pretax portfolio variance but to replicate her pre-tax expected portfolio return. To accomplish that objective she would have to further enlarge her investment in the risky asset, thereby taking on

\footnotetext{
Aversion," 96 Am. Econ. Rev. 1821 (2006).

52 See, e.g., Bankman \& Fried, supra note 4, at 542-44; Cunningham, supra note 3, at 31-35; Schenk, supra note 3, at 426-27; and, to some extent, Bankman \& Griffith, supra note 4, at 392-96. Most studies qualify their conclusions as requiring full loss offsets, scalability of investments, and the absence of price effects from portfolio rescaling, but few even allude to the possibility that investor reactions will depend on their tolerance for risk. Bankman \& Griffith, while acknowledging their use of a preference representation (logarithmic utility) that is simply illustrative, seem to assume that any risk-averse actor will gross-up, perhaps because they use a zero riskfree rate in their illustration. See supra note 50. Specifically, they assert that to conclude that an income tax on risky investments is not unfair "is easy with respect to the individual investor: No unfairness is caused by the tax because the investor can adjust her portfolio to return to the precise position he [sic] enjoyed in the no-tax world." Id. at 395-96.
} 
even more risk. ${ }^{53}$ In our setting it is easy to show, as reflected in Warren's Example 4, that the required allocation between risky and risk free investments is $\alpha_{0}=0.8571$ and $1-\alpha_{0}=0.1429$. The after-tax portfolio outcome is then: ${ }^{54}$

\begin{tabular}{||rcrr||}
\hline \multicolumn{5}{|c||}{ EXAMPLE 4 } & & \\
Income Tax: Adjustment to Replicate Pre-Tax (Expected) Return & \\
& Riskless (2\%) & Risky (8\%) & Total \\
Investment (After-Tax) & $\$ 14.29$ & $\$ 85.71$ & $\$ 100.00$ \\
Pre-Tax Return & $\$ 0.29$ & $\$ 6.86$ & $\$ 7.15$ \\
Tax & $\$ 0.09$ & $\$ 2.06$ & $\$ 2.15$ \\
After-Tax Return & $\$ 0.20$ & $\$ 4.80$ & $\$ 5.00$ \\
Investment Plus Return After Tax & $\$ 14.49$ & $\$ 90.51$ & $\$ 105.00$ \\
\hline
\end{tabular}

At that point Warren makes what at first glance is a puzzling and on reflection is a very odd claim ${ }^{55}$ : he characterizes Example 4 as somehow confirming that, compared to a cash flow tax, the income tax here falls on the riskless rate of return applied to the investor's entire portfolio. It is puzzling because, whether as exemplified by Example 4 or considered in the abstract, by construction that is not what this portfolio does. With the stipulated change in allocation the expected return after-tax is not less than but the same as -- albeit more risky than ${ }^{56}$-the expected return on the original portfolio in a no tax world (Example 0), or under a cash flow tax in response to which the investor grossed up the entire portfolio (Example 2). After adjustment and after tax, the expected return on this portfolio -- 5 percent -- is as though neither the

53 Warren II, supra note 3, at 10. The pre-tax return is replicated by enlarging the holding of the risky asset to the point at which it produces an after-tax return sufficient to offset entirely the impact of tax on the original portfolio. The assumption implicit in this adjustment is that the wealth derivative of the optimal holding of the risky asset (see supra note 49) is negative, so that the investor's holding of that asset declines as her wealth grows, i.e., she exhibits increasing absolute aversion to risk. The intuition for the sign of the adjustment is that the tax reduces her wealth, to which she again responds by increasing her pre-tax holding of the risky asset, this time to a point at which the after-tax return on that asset (and after-tax private risk) exceeds that in a no-tax world.

54 The new allocation, which I denote by $\alpha_{0}$ (see supra note 27 ), must satisfy

$$
\begin{aligned}
& 1+\alpha_{0} \mathrm{P}(1-t)+\left(1-\alpha_{0}\right) r(1-t)=1+\alpha \mathrm{P}+(1-\alpha) r \\
& \Leftrightarrow \alpha_{0}=\frac{\alpha}{1-t}+\frac{r t}{(1-t)(\mathrm{P}-r)}=\left[\alpha+\frac{r t}{\mathrm{P}-r}\right] \frac{1}{1-t} .
\end{aligned}
$$

55 His exposition actually entails two different alternative adjustments and two related claims, the second of which involves a collateral shortcoming, and is in any event inessential to his argument. See infra note 65.

56 The calculated after-tax standard deviation of $\$ 85.71$ invested in the risky is $\$ 4.16$, or $\$ 4.16 / \$ 3.46=120 \%$ of that of the original pre-tax portfolio. Compare supra notes 9-10. That is consistent with the fact that the return to the risky asset has risen from $\$ 4$ in Example 0 to $\$ 4.80$ after-tax in Example 4 , or by $\$ 4.80 / \$ 4.00=1.20$. 
risky nor the riskless return had been taxed. ${ }^{57}$ Comparing cash flow taxation with income taxation using this particular portfolio adjustment the riskless return is exempt in exactly the same sense as the risky return is exempt, both here and in Example 3.

What then is the basis for Warren's contrary claim? According to Warren, the possibility that the investor might choose some different allocation
does not change the conclusion that the only difference in results between income and cash flow taxation is the taxation of the riskless return on the investor's entire portfol- io, because explicit taxation of only that return would reduce the taxpayer's resources to the same extent. After taking into account the effect, if any of this reduction, the taxpayer's opportunities would be identical under the income tax and a tax explicitly limited to the riskless rate of return. ${ }^{58}$

But the italicized language isn't a statement about the comparative impact of income and cash flow taxation. It is, rather, an observation about the feasibility of replicating the outcome under a conventional income tax, levied on the returns from both of two investments, with a system that expressly exempts one and taxes the other as though earned on the entire portfolio. That this is what Warren intended appears to be confirmed by the balance (which henceforth I call Example 4A) of his Example 4, in which he continues:

[Example 4A] The same result [an expected return of 5 percent] could be accomplished under a tax that explicitly taxed only the riskless return on the entire portfolio by investing $\$ 60$ in the risky asset and $\$ 40$ in the riskless asset. The riskless asset would always produce $\$ 40.80$, the tax due [on $0.02 * \$ 100=\$ 2$ ] would always be $\$ 0.60 \ldots$, and the risky investment would produce [an expected return of $\$ 64.80$, for] a total expected return of $[\$ 40.80-\$ 0.60+\$ 64.80=] \$ 105 .{ }^{59}$

That, too, does not speak to the "difference in results between income and cash flow taxation". What it illustrates, as outlined at the conclusion to Part II, is simply that the conventional income tax outcome in a portfolio adjusted as in Example 4, no less than in Example 3, can in principle be replicated by some transformation of that portfolio, subjected to a tax that was actually limited to the riskless return as though earned on the entire portfolio. That is what the portfolio in Warren's Example 4A actually does. But the fact that it does provides no insight into the comparative impact of income and cash flow taxation on the holder of a portfolio such as that set up

57 Algebraically, when the portfolio allocation required to satisfy the investor's postulated objective is substituted into the taxable portfolio, the expected after-tax return is just

(here $\alpha=0.50)$.

$$
1+\alpha \mathrm{P}+(1-\alpha) r,
$$

58 Warren II, supra note 3, at 9 (emphasis added).

59 Id . at 10. 
as our original object of study in Example 0. From any such starting point there is an uncountable number of ways -- of which in this instance Examples 3 and 4 illustrate only two -- in which the holder might in principle respond to income (as contrasted with cash flow) taxation. For each such response we can construct a portfolio that would reproduce the same results under the "riskless return only" alternative posited by Warren in Example $4 \mathrm{~A} .{ }^{60}$ All of which says that (1) we can study the effect of different responses to a conventional income tax, (2) we can study the corresponding outcomes under the alternative scheme posited by Warren, and (3) the two will be systematically related. Of those three, what the latter two address is simply the characteristics of an alternate system that is "equivalent" to a conventional income tax in the sense that, in terms of feasible after-tax combinations of risk and return, it produces identical "opportunity sets" for the taxpayer. ${ }^{61}$ They do not, however, tell us what the taxpayer's response to an income tax-item (1) on that list -- will actually be.

As developed in Part III, her actual response will depend on her tolerance for risk. If she were to choose to replicate after tax her original pre-tax level of risk (Example 3 ), ${ }^{62}$ the expected outcome would equal the pre-tax return on her original portfolio reduced by tax on the risk free rate, and would differ by that much from the cash-flow tax outcome. If, instead, she were to choose to replicate her original expected return (Example 4), exhibiting some measure of increasing absolute aversion to risk, her portfolio would then be more risky than it was under a cash flow tax (or without taxes) but its after-tax expected return would be the same. And that would not be altered by the fact that the same outcome could also be replicated under a "riskless return only" equivalent tax, as Warren illustrates in Example 4A. If it were, the replicating portfolio would not -- and in Warren's example does not -- have the same coefficients as the original port-

60 See supra note 33.

61 Warren II, at 9; Weisbach, supra note 3, at 18; cf Shuldiner, supra note 3, at 15-16; Kaplow (1994), supra note 3, at 792-93. (The terminology is borrowed from the finance literature on portfolio construction. See, e.g., Bodie, Kane \& Marcus, InVESTMENTS 178-83 (2d 1993).) Some, including Shuldiner and, in particular, Weisbach, supra note 3 , argue that the existence of a risk-free return only equivalent system by itself somehow decisively undermines the insight, common to virtually all economic modelling of the problem (see Part III), that adjustments to holdings of risky assets will be influenced by the interaction of risk tolerance and the impact of taxation on wealth. That argument is sufficiently unqualified and apparently influential to warrant explicit consideration below. See infra, text and notes at notes 78-81. For the moment it suffices to say that, even if a conventional income tax and a tax on the risk-free return as though earned on the entire portfolio leave equivalent risk-return combinations open to the taxpayer, the actual incidence of an income tax will depend on which point in those opportunity sets -which particular combination of risk and return -- the taxpayer actually chooses.

62 See supra text and notes at notes 48-49. 
folio (Example 0). It would not differ from a cash-flow tax by tax on the riskless return on the entire portfolio. It, too, would have the same expected return as -- not the same risk but lower expected return than -- the original portfolio.

Faced with a cash flow tax the investor can replicate both her pre-tax risk and expected return. Under an income tax, in contrast, she can replicate one (Example 3), the other (Example 4), or (at least in principle) any convex combination of the two. ${ }^{63}$ What she cannot do is replicate both. And nothing in either Example 3 or 4 -- or in the fact that the outcome in each might be duplicated under a tax on the riskless return -- tells us what (if anything) the investor will actually do, or which (if any) of those possibilities we should take as the decisive comparison. From some common point of departure, the appropriate comparison is of (a) the point in the set of feasible outcomes that is chosen once a conventional income tax has been imposed, to (b) what the investor would have chosen in the absence of tax (or under a cash flow tax), not (c) whether the former can be replicated under an equivalent alternative to an income tax. ${ }^{64}$ Only the latter is illustrated by Warren's Example 4A.

From one perspective the argument might reasonably stop there. The central observation of Part III of this paper is that the way in which investors actually respond to income tax will depend on their tolerance for risk. The point of Part IV has been this: we can replicate the outcomes under a conventional income tax by explicitly taxing some systematically transformed portfolio as though the entire portfolio had earned the riskless rate of return; that does not, however, tell us whether any particular investor will actually respond to an income tax by transforming their portfolio in that fashion. Much of the literature following Warren takes him as standing for the proposition that it does. But all that Example $4 \mathrm{~A}$ really illustrates is the feasibility of a "riskless

63 Indeed, Examples 3 and 4 together illustrate that under an income tax she can adjust her behavior to achieve either but not both those objectives; the point of Example 2 is that under a cash-flow tax she can replicate both.

64 Weisbach, supra note 3, at 6, evidently on the premise that, in response to an income tax, investors either do or do not gross up ("adjust" in his terminology) -- and in his view they do -- argues that as long as investors "make investments based on after-tax returns ... . they will implicitly have made all the calculations and adjustments required by the models", and so may be taken to have "fully adjust[ed] to taxation." See also id. at 42-47. Even in theory, however, the economics do not furnish the prediction on which Weisbach's argument rests. As surveyed in Part III, there is theoretical ambiguity about what investors optimally should and hence practical uncertainty about what they actually will do. Weisbach's claim side-steps the pivotal question, an answer to which is essential to assessing the actual burden of an income tax on risk: what would the investor have done in the absence of a tax? Given the range of possibilities -- both theoretical and practical -- the answer cannot be inferred, as Weisbach would have it, simply from observing what she actually has done in the presence of a tax. See infra text and notes at notes 82-84. 
return only" equivalent to a conventional income tax.

Sensing, perhaps, that something is still missing from the analysis, however, Warren himself doesn't stop there. In an effort to substantiate the claim that these examples illustrate that the essential difference between income and cash-flow taxation is taxation of the riskless return, the final step in Warren's account is to compare both the riskless-return-only and conventional versions of an income tax to the two principal consumption tax equivalents, the "yield exemption" (or "prepayment") version and the cash flow tax itself. ${ }^{65}$ In making that comparison, at least if we take at face value Warren's portfolio coefficients, ${ }^{66}$ the exact illustration of an income tax he appears to employ is that of Example 4, in which the investor has adjusted her holdings to replicate after tax the expected return she would have enjoyed in a world without tax, and its riskless-return-only counterpart in Example 4A. His tack is to proceed from a comparison of the yield exemption version of a consumption tax (denoted "tax (4)") to the riskless return only version of an income tax (Warren's "tax (1)"), to infer something decisive about the relationship -which he characterizes as otherwise "not immediately apparent" -- between a conventional income tax (his "tax (2)") and a cash flow tax ("tax (5)"). From that comparison Warren concludes "that

65 Warren II, at 12, denotes the cash flow tax itself "tax (5)"; and denotes by "tax (4)" the yield-exemption equivalent, under which assets are paid for with after-tax outlays but asset yields (that is, income from property) are explicitly exempt, so that tax is explicitly confined to labor income (e.g., a wage tax) as illustrated in Example 2A, below. Id. at 11-12. See Andrews (1974), supra note 1, at 1120-25; Graetz, supra note 1, 1597-1602.

What appears here as peculiar numbering for a comparison of four tax systems stems from the fact that Warren's analysis includes an additional example, characterized as replicating an income tax with a tax levied on the risky return as though earned on the entire portfolio. Warren II, supra note 3, at 10-11 (Example 5). It can be shown, however, that this second alternative replicates the after-tax return under a conventional income tax only at higher risk, and is not truly an "equivalent" system. In Warren's complete comparison of three versions each of an income tax and a consumption tax, the "risky return-only" (income) tax is "tax (3)", while its consumption tax counterpart (Warren's "tax (6)") would tax the entire portfolio on the excess of the risky return over the risk-free return. Both are omitted from the discussion in text. A separate analysis of their non-equivalence is available from the author.

66 Warren is not completely explicit about his definitions, but by his introducing the coefficient â in connection with his Example 4, at 10, one may infer that, corresponding to some coefficient a in a no tax world, Warren denotes (1) by $\hat{a} /(1-t)$ the coefficient on the risky asset under a conventional income tax adjusted to replicate after-tax the investor's original expected return (equivalent to $\alpha_{0}$ here); and (2) by â a portfolio to achieve the same objective under an income tax confined to the risk-free return (equivalent to $\gamma_{0}$ here); It is these coefficients that Warren appears to have used on his "income tax equivalents" in his income tax/cash flow tax comparisons. Id. at 11-12. The implication of using different coefficients is taken up below. (Warren's $a^{\prime}=\hat{a}+t$ is the coefficient on the risky asset adjusted to produce the same expected return under a tax confined to the risky return, omitted from consideration here). 
the difference between taxes (2) and (5) is taxation or exemption of the riskless return, because that is the difference between taxes (1) and (4)."67

The difficulty is that, given his choice of coefficients, Warren's example does not conform to his stated premise that "the difference between taxes (1) and (4)" is "is taxation or exemption of the riskless return." That is, neither version of the income tax he uses for comparison has the effect of taxing the riskless return. The conventional income tax illustrated in Example 4 replicates the investor's pre-tax expected return from Example 0, equivalent to exempting both the risky and the risk free return from tax; by construction, the same is true of Warren's "riskless return only" alternative illustrated in Example 4A. The shortcoming is that Warren's comparison of his "cash-flow tax equivalents" with what he denotes their corresponding "income-tax equivalents" depends on what he has chosen as baseline portfolios for each species of tax. One would have thought that the most natural point of departure for both would be some common portfolio (such as Example 0) in a no tax world, but that is not what Warren has done. Instead he appears to have chosen Examples 0 and 2 as his cash flow tax equivalents, but Examples 4A and 4 -- not Example 3 -- as their income tax "counterparts", and by that choice has undermined the point he is trying to make.

Can the argument be strengthened by a better choice of examples? The answer is yes, but the choice doesn't advance the case by very much. The difference between a "riskless return only" tax (Warren's "tax (1)") and the yield exemption alternative to a cash flow tax ("tax (4)") will be exactly taxation or exemption of the riskless return only when the "riskless return only" portfolio used in the comparison has been constructed to satisfy that condition. For an arbitrarily chosen baseline portfolio in a no-tax world, that will be so only when the coefficients under the riskless return only system are identical to those in the baseline. To illustrate using as a baseline Example 0, the cash-flow tax counterpart of which is illustrated in Example 2, the investor's behavior under the yield exemption alternative -- no tax at all -- presumably wouldn't change from that in the baseline portfolio:

67 Id. at 11. 


\begin{tabular}{|c|c|c|c|}
\hline \multicolumn{4}{|c|}{$\begin{array}{l}\text { EXAMPLE 2A } \\
\text { Yield exemption Equivalent Consumption Tax (No Portfolio Adjustment) }\end{array}$} \\
\hline & Riskless $(2 \%)$ & Risky (8\%) & Total \\
\hline Investment (After-Tax) & $\$ 50.00$ & $\$ 50.00$ & $\$ 100.00$ \\
\hline Pre-Tax Return & $\$ 1.00$ & $\$ 4.00$ & $\$ 5.00$ \\
\hline Tax & $\$ 0.00$ & $\$ 0.00$ & $\$ 0.00$ \\
\hline After-Tax Return & $\$ 1.00$ & $\$ 4.00$ & $\$ 5.00$ \\
\hline Investment Plus Return After Tax & $\$ 51.00$ & $\$ 54.00$ & $\$ 105.00$ \\
\hline
\end{tabular}

The return to an identical portfolio under a riskless return only tax system would be:

\begin{tabular}{||crrr||}
\hline \multicolumn{3}{|c||}{ EXAMPLE 3A } & \\
Income Tax on Return to Riskless Investment (on the Entire Portfolio) & \\
& Riskless (2\%) & Risky (8\%) & Total \\
Investment (After-Tax) & $\$ 50.00$ & $\$ 50.00$ & $\$ 100.00$ \\
Pre-Tax Return & $\$ 1.00$ & $\$ 4.00$ & $\$ 5.00$ \\
Investment Plus Return & $\$ 51.00$ & $\$ 54.00$ & $\$ 105.00$ \\
Tax on Risk free Return & & & $\$ 0.60$ \\
Investment Plus Return After Tax & & $\$ 104.40$ \\
\hline
\end{tabular}

With Example 0 as the baseline, then, Example $3 \mathrm{~A}$ illustrates the portfolio under a riskless return only tax that differs from the yield exemption version of a consumption tax (Example 2A) by exactly taxation (across the entire portfolio) of the riskless rate of return. It has the same coefficients as the portfolios under both the yield exemption tax and the baseline. But what, under a conventional income tax, corresponds to that particular portfolio in the sense of producing equivalent results? That would be Example 3, in which the original investment in the risky asset was grossed up to replicate after tax the pre-tax outcome from that investment. But that is precisely the example that gave rise to Warren's insight in the first place: under a conventional income tax, grossing up the holding of the risky asset produces a result equivalent to taxing the riskless return across the entire original portfolio (Example 3). So it should come as no surprise that restoring the original coefficients of that portfolio accomplishes the same thing under a tax explicitly limited to the riskless return. ${ }^{68}$

68 See supra note 33. 
In other words, the premise of the comparison Warren undertakes of income and cash flow taxation -- that the yield exemption version of a consumption tax differs from the corresponding riskless return only version of an income tax by exactly taxation of the riskless return across the entire portfolio -- is valid only when the latter has been constructed to satisfy that condition, which requires that the portfolio coefficients be identical to those in the baseline portfolio. When they are, it follows immediately that the corresponding (i.e., grossed-up) portfolio coefficients under the conventional income tax are precisely those under which the latter does actually differ from a cash-flow tax by taxation of the riskless return. ${ }^{69}$ In any other case Warren's premise is not valid and his more general inference about the comparative properties of income and cash flow taxation does not follow.

Putting aside the details of the portfolios Warren used in developing the argument, there is a perhaps simpler way of interpreting his point. Perhaps what he intended is the abstract claim that a tax levied only on the riskless return as though earned on the entire portfolio bears the same relationship to a conventional income tax as the yield exemption version of a consumption tax bears to a cash flow tax, in the sense that exactly the same adjustments must be employed to achieve equivalence in either case. That is certainly so. And it is tempting to reason from the congruence of those adjustments that, since the difference between a yield exemption consumption tax and the riskless return only version of an income tax appears to be taxation of the riskless return, that must also be the difference between a conventional income tax and a cash-flow tax. In general, however, as suggested above, the posited difference does not necessarily characterize either relationship.

The fly in the ointment is this. While a yield exemption tax and a cash-flow tax are equivalent, they also either are, or are equivalent to, no tax on capital income at all. So imposing neither should have any wealth effect, something that is self-evident with a yield exemption tax and, with the portfolio adjustment needed to achieve equivalence, is likewise true of the cash-flow tax, as reflected in the taxpayer's ability to recover through that adjustment her pre-tax combination of risk and return. The same cannot be said of either form of income tax, both of which can

69 That is, the coefficient on the risky asset under the risk free return only tax is identical to that in the baseline portfolio (say $\alpha$ ) and under a yield-exemption consumption tax; the corresponding coefficient under the cash-flow counterpart is $\alpha /(1-t)$; and the latter is also the coefficient on the risky asset in a portfolio adjusted from the same baseline under an income tax to preserve the pre-tax outcome on the risky investment, which also is equivalent to taxing the risk free return across the baseline portfolio. 
in principle have such effects. ${ }^{70}$ It is true if -- and, with a positive interest rate, only if -- the investor is assumed to respond to imposition of the conventional version by grossing up her holding of the risky asset. In that case (and only that case) the difference between the income tax and a cash flow tax (or its yield exemption equivalent, aka no tax at all) will indeed be taxation of the riskless return; and (with the appropriate adjustment) the same will be true of the explicitly riskless return-only equivalent tax. But, as illustrated by Warren's own Example 4, it will not hold if her preferences lead her to some different adjustment to the conventional tax; and, if it doesn't, it won't hold under the corresponding riskless return only equivalent tax, either, because the coefficients on the portfolio adjusted to achieve equivalence will not be the same as the original portfolio coefficients, That is to say, when wealth effects are taken into account, the difference between a yield-exemption tax and the riskless return-only version of an income tax will not necessarily be taxation of the riskless return. That, too, is illustrated by Example 4. If, as in that example, the investor adjusted her portfolio to hold $\left(\alpha_{0}=\right) \$ 85.71$ of the risky asset, and if the equivalent result under a riskless return-only alternative is achieved by holding $\left(\gamma_{0}=\alpha_{0} *(1-t)=\right)$ $\$ 60$ in the risky asset, then a comparison of the outcomes in a no-tax world (Example 0), under the yield exemption version of a consumption tax (Example 2A), and under a tax confined to the riskless return (Example 4A), would establish that the latter (and therefore its conventional counterpart) is equivalent, not to a tax on the riskless return, but to no tax at all. Even with this reformulation, then, the premise that a riskless-return only tax differs from the yield exemption version of a consumption tax by tax on the riskless return holds only when imposing the former has no impact on the investor's (after-tax) optimal holding of the risky asset, which is to say, only when in response to the conventional income tax the investor would exactly gross up.

This entire discussion may be summarized by a picture, which I follow with a final pair of examples. The illustration depicts the effect of income taxation in the space of portfolio expected return and standard deviation (so-called mean-variance or $\mu / \sigma$ space). ${ }^{71}$ There the relationship between risk and expected return as the portfolio varies from holding only the riskless $(\alpha=0)$ to only the risky $(\alpha=1)$ asset is given by the solid straight line $(\mathrm{N})$ that intercepts the $\mathrm{Y}$

70 The argument here responds also to the proposition that it is inconsistent to think that investors will grossup holdings of risky assets in response to an cash-flow tax but might not when confronted with an income tax. Weisbach, supra note 3, at 7 \& n. 18; see Bankman \& Fried, supra note 4, at 543.

71 It is inspired by Shuldiner, supra note 3, at 15-16. See, e.g., Bodie, Kane \& Marcus, supra note 61, at 17981. 
(expected return) axis at $E_{\mathrm{p}}=r=0.02$, when the portfolio holds only the riskless asset and its standard deviation is 0 . The line slopes upward to the northeast, since both return and standard deviation scale up by the same factor as the holding of the risky asset increases. Under an income tax imposed on portfolio returns the risk/return line shifts down (to the dashed line, A) by the product of the tax rate $(t)$ and the riskless return $(r){ }^{72}$

72 Given a risky asset with expected return $\mathrm{P}$ and standard deviation $\sigma$ and a riskless return $\mathrm{r}$, the expected return $\left(E_{\mathrm{p}}\right)$ and standard deviation $\left(S_{\mathrm{p}}\right)$ of a $(\$ 1)$ portfolio with $\alpha$ allocated to the risky asset are given by

$$
\begin{aligned}
& E_{p}=\alpha \kappa_{\tilde{R}} \mathrm{P}+(1-\alpha) \kappa_{r} r, \text { and } \\
& S_{p}=\alpha \kappa_{\tilde{R}} \sigma
\end{aligned}
$$

where $\kappa_{\tilde{\mathrm{R}}}$ and $\kappa_{\mathrm{r}}$ are parameters characterizing taxation of the risky and riskless assets, respectively. Eliminating $\alpha$ and solving for $E_{\mathrm{p}}$ gives an expression for expected return as a function of $S_{\mathrm{p}}$ in slope-intercept form:

$$
E_{p}=\kappa_{r} r+S_{p}\left(\frac{\kappa_{\dot{R}} \mathbf{P}-\kappa_{r} r}{\kappa_{\tilde{R}} \sigma}\right) \text {. }
$$

Linearity stems from the fact that both portfolio expected return and standard deviation rescale with the holding of the risky asset; see supra note 9 . If the return from neither asset is taxed the tax parameters are $\kappa_{\tilde{\mathrm{R}}}=\kappa_{\mathrm{r}}=1$, and the equation becomes

$$
e E_{p}=r+S_{p}\left(\frac{\mathbf{P}-r}{\sigma}\right)
$$

If both assets are taxed at a common rate $t$, the tax parameters become $\kappa_{\tilde{\mathrm{R}}}=\kappa_{\mathrm{r}}=1-t$, and the expression becomes

$$
E_{p}=(1-t) r+S_{p}\left(\frac{\mathbf{P}-r}{\sigma}\right)
$$

where the intercept (at $S_{\mathrm{p}}=0$ ) has shifted down by -tr but the slope coefficient is unaffected by the tax. 
Figure 1

Income Tax Possibilities (In $v / \sigma$ Space)

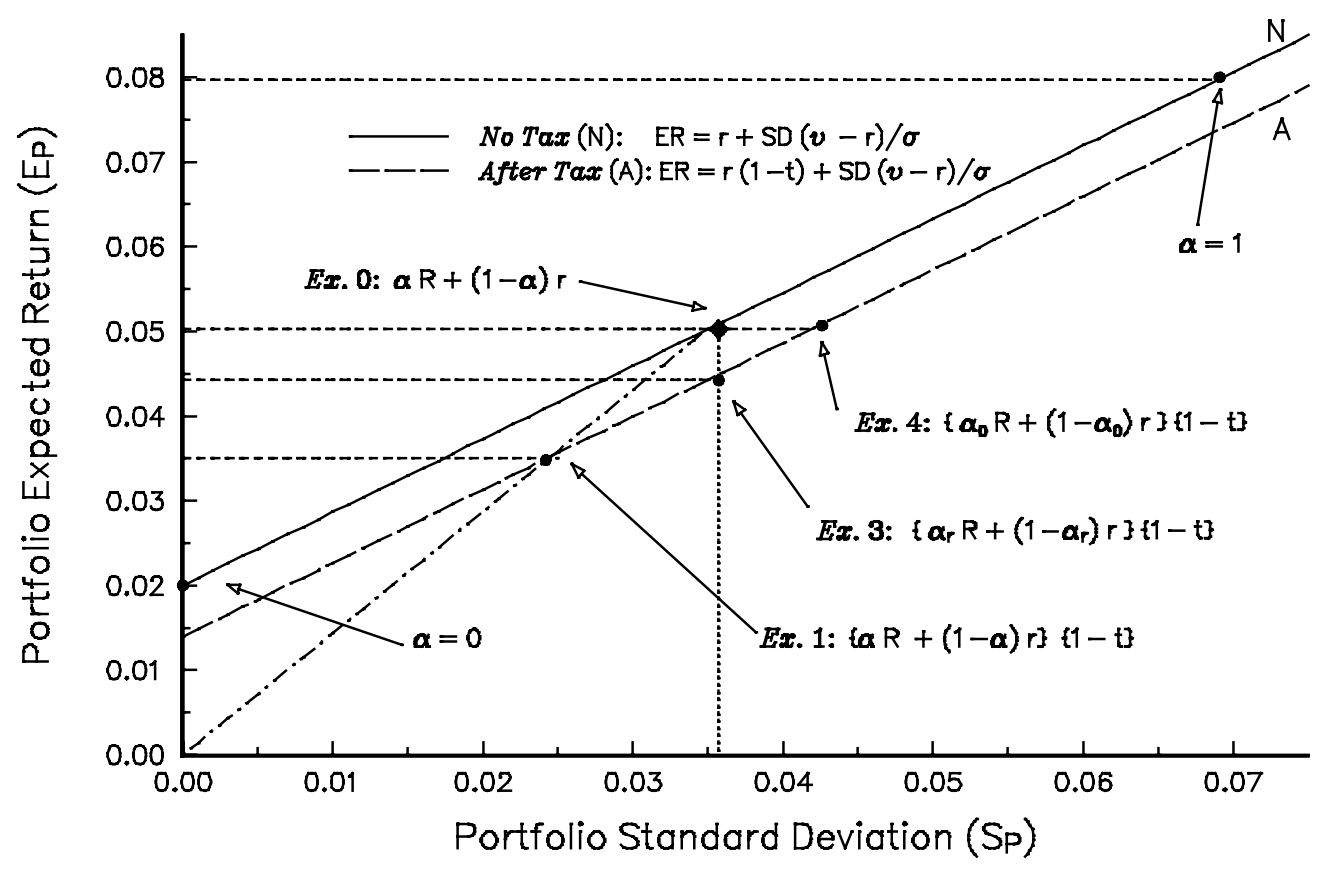

That shift might be interpreted ${ }^{73}$ in a manner consistent with Warren's claim that the essential difference between income and cash flow taxation is taxation of the riskless return, which at first glance seems to be corroborated by Figure 1. The vertical line that intersects both the original portfolio (denoted "Ex.O") and Example 3 ("Ex.3") does appear to (and algebraically does) involve a reduction in yield after-tax by exactly $\operatorname{tr}$ (here 0.006). But appearances in that picture must be interpreted with care. A vertical line in the Figure represents portfolios that, as the result of taxation, differ in their expected returns but have the same standard deviation. Hence, two portfolios of given initial wealth containing the same two assets -- one on the pre-tax risk/return line, the other on the after-tax line -- differ by exactly $\operatorname{tr}$ (and so fall on the same vertical line) only if the holdings in the latter have been adjusted to preserve after tax the original portfolio risk, which is to say only if the original portfolio holding of the risky asset has been grossed up. If in response to an income tax, as developed in the examples above, the investor has made some other adjustment (or no adjustment at all), then what the same Figure illustrates is that the returns to the pre-tax and after-tax portfolios will differ by some other amount. If, for example, the investor made no adjustment ("Ex.1" in the Figure) her after-tax expected return

73 See, e.g., Shuldiner, supra note 3, at 16. 
would be scaled down by the tax rate to 3.5 percent; and if she adjusted her holdings as in Example 4 she could replicate her original pre-tax return (point "Ex.4") at higher risk. ${ }^{74}$ In principle, moreover, any point on the after-tax risk/return line is open to the investor; so in principle the impact of imposing an income tax on one whose preferences led her to chose the point Ex.O in a no-tax world (or under a cash flow tax) is not captured by the downward shift in the risk-return line (her risk-return "opportunity set") alone; even with that shift the actual burden of the tax will depend on which point on the new risk-return line she happens to choose. Some points on that line will be more plausible than others. But it is not obvious that she would choose simply to gross up her holding of the risky asset; and, as outlined in Part III, economic modelling suggests that she would not.

The argument that, in a model of the impact of taxation on choices involving risk and return, an income tax can be viewed as systemically equivalent to a tax on the riskless return turns on the proposition that, if (say) confronted serially with those two equivalent systems, an investor who chose a portfolio that produced a particular after-tax combination of risk and return under one system would choose the (different) portfolio that produced the same outcome (and the same combination) under the other. While that presupposes a level of financial sophistication that is possibly not warranted by casual observation it is not a priori unreasonable to believe that, given the requisite financial acumen, that is what economic actors might do. The equivalence of the two systems is captured by the fact that the outcomes under both fall on the same line -- the aftertax line (A) -- in Figure 1. ${ }^{75}$

74 Indeed, in lieu of conceiving of the risk/reward line as shifting down (to reflect reduced return at every pretaxation choice of risk) as a result of taxation, one might as readily (if perhaps not quite as easily) think of it as having shifted right to reflect increased cost (in terms of added risk) of reproducing pre-tax expected return at every pre-taxation choice of expected return. Solving the equation for $E_{\mathrm{p}}$ in note 72 for $S_{\mathrm{p}}$ produces (in the presence of taxation)

$$
S_{p}=-(1-t) \frac{r \sigma}{\mathrm{P}-r}+E_{p} \frac{\sigma}{\mathrm{P}-r}
$$

which says that the added risk needed to achieve after-tax any given pre-tax return is

$$
t \frac{r \sigma}{\mathbf{P}} \text {. }
$$

75 I credit Alvin Warren with this felicitous formulation. It follows from the fact that each pair of equivalent outcomes is equivalent in the sense that they produce the same combination of risk and return. Hence, not only do they all fall on the after-tax line (A); each pair falls at the same point on that line. Recall by way of illustration that the overall outcomes under the risk free return only tax portrayed in Example 3A (where the original risk is preserved after-tax) and Example 4A (where the original expected return is preserved) are identical to those in Examples 3 and 4, respectively. Recall also that the expected after-tax returns to the risky asset are also the same for each pair of examples, so that the after-tax risk is also the same for each pair. See supra notes 9-10. Hence 
It is, however, a different and much stronger claim that if forced to transit from a world without taxes to one with an income tax, with a concomitant reduction in her wealth, what an economic actor would care most about preserving is her pre-tax level of risk, exhibiting constant absolute aversion to risk, and that what she therefore will do in response would be to gross up her holding of the risky asset. But it is on precisely that premise that the claim that, compared to a cash flow tax, the burden of an income tax is taxation of the riskless rate rests. While that is one possibility it is not inconceivable that what investors would like to preserve after-tax is their pre-tax return, exhibiting increasing absolute aversion to risk, and Figure 1 might as readily be given that interpretation. ${ }^{76}$ In truth, neither of those accounts is especially plausible. In the presence of relatively well-behaved preferences over risk and return it is most plausible that an actor who was optimizing in the absence of taxes would choose an after-tax reallocation that fell somewhere between Ex.1 and Ex.3 in Figure 1. That is, the investor most plausibly would respond to taxation by enlarging her holding of the risky asset, but by something less than fully grossing it up. ${ }^{77}$ In that event, her after-tax outcome, compared to her original portfolio, will be as though she were exposed to less risk, and were taxed on something more than just the risk free rate. Whatever she chooses, the crucial point, illustrated by Figure 1, is that the burden of an income tax will depend on what she actually does choose, and so at which point on the aftertax line her portfolio outcome actually falls.

A contrary view can be found in the literature, reflected in assertions such as that "given the amount of risk he has chosen to bear," as reflected in the portfolio the taxpayer is observed to have chosen, his "reduction in yield is equal to" $t r,{ }^{78}$ a conclusion that appears to be animated by beliefs such as that:

For any given after-tax portfolio, the tax burden can be measured by the vertical distance between the after-tax portfolio line and the pre-tax portfolio line. Since the lines are parallel, that vertical distance is always the same. ${ }^{79}$

the risk/return combinations in Examples 3A and 4A, if plotted on Figure 1, fall at the same points on the after-tax line as Examples 3 and 4, respectively, and the same will be true of every other pair of equivalent outcomes under a conventional income tax and a tax on the risk free return,

76 See supra, text and notes at notes 53-57; note 74.

77 She would, in other words, exhibit some degree of decreasing absolute aversion to risk. See notes 43 and 51.

78 Shuldiner, supra note 3, at 16.

79 Ibid (emphasis added). Shuldiner's conclusion seems ironic, given that he approaches the issue acknowledging that, in the presence of an income tax "it is no longer apparent how the taxpayer would wish to trade off risk and return" (id. at 11,15); and illustrates the problem using an example in which, given normal preferences for 
Assertions of that sort are not substantiated, and do not seem obviously correct. ${ }^{80}$ At the risk of repetition, it is correct to say that the vertical distance measures the impact of an income tax on equal (initially) sized no- and after-tax portfolios of equal risk. For an untaxed portfolio to have the same risk as a given after-tax portfolio its holding of the risky asset must have been scaled down by $(1-t)$. But the difference between the returns to those two is a measure of the income tax burden on the given after-tax portfolio only to someone who would have held the scaled-down counterpart in the absence of tax. If, in contrast, because of the interaction between her risk tolerance and the wealth effect of the tax, she would have chosen some different holding of the risky asset, and therefore a portfolio with a different variance in a pre-tax world, then it

risk and return and confronted with an income tax, the taxpayer chooses something less than a fully grossed-up holding of the risky asset, leading Shuldiner to observe that "the taxpayer is bearing less risk than he bore pre-tax and his return has decreased by more than" tr. Id. at 16.

80 To much the same effect as Shuldiner is Weisbach (at 18):

"One subtlety in the last example is that the government collects real tax dollars on the risk-free return and $\mathrm{T}$ correspondingly pays real taxes. $\mathrm{T}$, therefore, is poorer. Being poorer, $\mathrm{T}$ might desire to enter into a different amount of risk. T might change his investments and, therefore, taxation will affect risk bearing . . . In economics lingo, there is a wealth effect.

"But compare two tax systems. One taxes the risk-free return to investments and the other nominally taxes the entire return (a traditional income tax). There will be no wealth difference in these two taxes because both collect the tax on the risk-free return and only that tax. The two taxes are identical in the sense that any opportunity available under the traditional income tax can be achieved under the risk-free-return tax and vice versa. Therefore, behavior has to be the same under both taxes and we need not worry about wealth effects."

Strictly speaking, it is not correct to say that both taxes "collect the tax on the risk-free return and only that tax." One does; the other (possibly) leaves the taxpayer in the same after-tax position as if it had. Nor is it necessarily (or even typically) the case that behavior would be "the same under both taxes." They in fact produce equivalent results only if behavior under the two is different, in that a taxpayer who chose some particular holding of the risky asset under a risk-free return only tax would choose its grossed-up counterpart under a conventional income tax. But putting those details aside, and granting the feasibility of equivalent results under a conventional income tax and a risk-free return only tax, nothing in the passage explains how or why the identity of opportunities under the two taxes justifies ignoring the possibility that the imposition of either will affect an investor's wealth, and in doing so may influence her appetite for risk. The posited equivalence tells us nothing about how (if at all) the investor (would have) altered her behavior in response to the imposition of either form of tax (see text and notes at notes 45-49).

Weisbach's argument has somewhat the same flavor as that of Kaplow (1991) and Kaplow (1994), supra note 3 , by which it seems to have been partly inspired; but it is not the same argument. Kaplow examined alternatives to income and consumption taxes assuming (as does Weisbach) that the government could (and did) offset the impact of tax-induced changes in behavior via portfolio activities of its own. The working-paper version (Kaplow (1991)) is somewhat more explicit on this point, and underscores that what is being studied are differences or equivalences among various taxes, assuming that tax has already been imposed. See supra note 15 . That assumption frees Kaplow from having to consider the effects of imposing tax to begin with, as the working paper expressly acknowledges. Id. at 4-6. But the equivalence between two taxes tells us nothing about the incidence in the first instance of either, a distinction not addressed by Weisbach. Hence, what Kaplow expressly excludes from his study -- the wealth effects of the imposition of tax on (for example) investors' risk tolerance -- Weisbach seems implicitly to assume away. 
will be the tax burden on the latter that is reflected in the after-tax outcome of the given after-tax portfolio.

At this juncture it bears recalling that this entire literature rests on the premise that to ascertain the impact of an income tax on a given portfolio we should compare the pre-tax outcome not with the after-tax outcome on the same portfolio but with the after-tax outcome after the investor has adjusted her holdings in response to taxation. ${ }^{81}$ Against that background it makes little sense to speak of the "tax burden" on a "given after-tax portfolio" at large. What a given after-tax portfolio says about tax burdens depends entirely on the pre-tax portfolio to which it is taken to correspond.

One final pair of examples will serve to make that observation concrete. They are, in effect, a more plausible version of what has already been illustrated by Example 4. Suppose that the taxpayer in our original example exhibited decreasing, rather than constant (Example 3) or increasing (Example 4), absolute aversion to risk, and responded to the advent of an income tax by increasing her holding of the risky asset, but to less than $\$ 71.43(=\alpha /(1-t)$ for that example). ${ }^{82}$ Suppose to be specific that she increased it by very modestly less, to $\$ 70$ instead. Her (expected) after-tax portfolio return would become:

\begin{tabular}{||rrrr||}
\hline \multicolumn{5}{|c||}{ EXAMPLE 6 } & & \\
Income Tax: Alternate Adjustment to Risky Investment & \\
& Riskless (2\%) & Risky (8\%) & Total \\
Investment (After-Tax) & $\$ 30.00$ & $\$ 70.00$ & $\$ 100.00$ \\
Pre-Tax Return & $\$ 0.60$ & $\$ 5.60$ & $\$ 6.20$ \\
Tax & $\$ 0.18$ & $\$ 1.68$ & $\$ 1.86$ \\
After-Tax Return & $\$ 0.42$ & $\$ 3.92$ & $\$ 4.34$ \\
Investment Plus Return After Tax & $\$ 30.42$ & $\$ 73.92$ & $\$ 104.34$ \\
\hline
\end{tabular}

\footnotetext{
81 See supra text at and preceding notes 15-16.

82 Since she is assumed to prefer more risk at higher wealth, she will respond to the reduction in her wealth implied by an income tax by reducing her (after-tax) risk. See supra notes 43 and 49.
} 
After tax this portfolio does not have the same variance as the original (50-50) portfolio in a notax world. ${ }^{83}$ The holding of the risky asset in the corresponding equal-variance pre-tax portfolio would be $\$ 70 *(1-t)=\$ 70 * 0.70=\$ 49$, leading to:

\begin{tabular}{||rrrr||}
\hline \multicolumn{4}{|c||}{ EXAMPLE 6A } \\
\\
Pre-Tax Counterpart: Alternate Adjustment to Risky Investment & \\
& Riskless (2\%) & Risky (8\%) & Total \\
Investment (After-Tax) & $\$ 51.00$ & $\$ 49.00$ & $\$ 100.00$ \\
Pre-Tax Return & $\$ 1.02$ & $\$ 3.92$ & $\$ 4.94$ \\
Investment Plus Return & $\$ 52.02$ & $\$ 52.92$ & $\$ 104.94$ \\
Tax on Risk-free return & & & $(\$ 0.60)$ \\
Investment Plus Return After Tax & & & $\$ 104.34$ \\
\hline \hline
\end{tabular}

Since the $\$ 3.92$ return to the risky asset in Example 6A is the same as that (after-tax) in Example 6 the standard deviation of both the risky asset and of the two portfolios is the same. ${ }^{84}$ Given the portfolio in Example 6, Example 6A is the no-tax portfolio with the same standard deviation, and hence differing from Example 6 by tax on the return to the risk free asset as though earned on the entire portfolio, as we have explicitly verified in the last two lines by subtracting the tax (\$0.60) on that return. But it is equally clear, given our assumption that Example 6 illustrates the adjustment to tax by an investor who would have chosen a 50-50 allocation in the absence of tax, that $\$ 0.60$ does not measure the burden of an income tax on her original portfolio. That burden would be given by the difference between the after-tax outcome in Example 6 and her pre-tax (5050 ) return of $\$ 5$. For our (modest) assumed adjustment that difference is $\$ 0.66$, not $\$ 0.60$, and for this particular assumption about how the taxpayer adjusts, that is the burden of an income tax on her original portfolio.

Example 6, of course, is just an illustration. But it, together with Warren's Example 4, provides an illustrative pair of counter-examples to the claim that, as a general matter, the burden of an income tax on (optimizing) investors in risky assets is equivalent to tax on just the risk free rate of return. In general it is no such thing. It has that property in the special (and not espec-

83 The calculated after-tax standard deviation of $\$ 70$ invested in the risky is $\$ 3.3948$, or $\$ 3.3948 / \$ 3.4641=$ $98 \%$ of that of the original pre-tax portfolio. Compare supra notes 9-10. That is consistent with the fact that the return to the risky asset has declined from $\$ 4$ in Example 0 to $\$ 3.92$ after-tax in Example $6 \mathrm{~A}$, or by $\$ 3.92 / \$ 4.00=$ 0.98 .

84 See supra note 9. 
ially plausible) case in which an investor's optimal holding of the risky asset is independent of her wealth, and she responds to an income tax exactly by grossing up her holdings of the risky asset. The belief that she might more generally behave in that way has heavily influenced our understanding of Domar \& Musgrave's work. But the basis for that belief was obtained on the simplifying assumption that the risk free rate either is (or is taxed as though it were) zero, an assumption that has largely been overlooked by a literature that persists in believing that grossing up is what any rational investor would do. ${ }^{85}$ When that assumption is relaxed, an investor's optimal holding of the risky asset, and hence the differential impact of income and cash-flow taxes on risk, will depend on the interaction of the wealth effect of taxation and her own tolerance for risk. To return to Warren's formulation of the question, the reason why the exact relationship between income and cash flow taxation is not more immediately apparent is that, in the final analysis, it is not captured by one particular way in which taxpayers have been taken as behaving but turns instead on what they actually do. And that remains so even if, for every possible way in which they might respond, the same result might be replicated under an equivalent to the income tax, explicitly limited to the riskless return.

\section{SOME CONCLuding ThOughts}

What implications does this have for the study of the interaction of income taxation and risk? From the perspective of the economics, not much. As noted in the Introduction and at the beginning of Part III, the central economic preoccupation has been with the possibly dampening effects of taxation on the disposition of economic actors to take risks, a concern that the findings of the literature seem long since to have allayed. While it is most plausible to believe that decreasing absolute risk aversion is the norm, and hence that private risk taking is to some extent reduced by an income tax, the most common belief, consistent with Domar \& Musgrave's original findings, is that aggregate social risk taking probably is not.

Most recent work has been devoted to the second question identified in the Introduction, how to characterize the impact of an income tax, given economic insights into how investors respond to risk. By this point it is safe to say that the belief that an income tax burdens only the riskless return is past being "absorbed into the conventional wisdom;" 86 it has become the

85 Warren does not fall into that trap, though he arrives at essentially the same conclusion via the somewhat different route under discussion here.

86 Bradford, supra note 4, at 224-25 \& n.5 
conventional wisdom. And the treatment of risk is one of two principal foundations for that belief, and the correlative claim that the difference between an income and a cash-flow consumption tax boils down to a tax on the riskless return. As developed in Part II, however, that insight is (in the two asset case) a simple algebraic consequence of grossing up the holding of one asset at the expense of the other. ${ }^{87}$ It breaks down if that is not what economic actors optimally or actually do. And, as surveyed in Part III, in general it is not. When deprived of that premise the possibility of characterizing in a simple qualitative way the comparative properties of income and cash-flow taxation to that extent disappears. The outcome will in some manner depend on economic actors' presumably heterogenous tolerances for risk. ${ }^{88}$

But the belief that an income tax burdens only the riskless return has become so firmly entrenched that a few cautionary observations are in order. It is, for one, useful to keep in mind that the algebra that generates the foundation for that belief is simultaneously illuminating and misleading: it illuminates the conceptual effect of grossing up asset holdings; it misleads because that illumination is obtained by eliminating from the algebraic expressions the factors that represent nominal taxes actually paid. I mention that because the notion that investors respond to risk by grossing up, and the algebraic consequence that when they do the outcome is as though they had made no portfolio adjustment but instead had been taxed on the riskless return, is so simple, striking, and downright beguiling that much of the work since Warren's comes close to treating that characterization not as an algebraic account of and conceptual gloss on but as a literal description of reality. Simple illustrations inspired by Example 3 have repeatedly been deployed to suggest that, whatever the data on tax collections (they are rarely consulted) might otherwise suggest, ${ }^{89}$ the income tax has "really" just been taxing the riskless return. If it is overstating

87 Although, as suggested by the Appendix, the results become more complex with more than two assets, it remains the case, for example, with several risky assets and a single safe asset, that equivalence to taxing just the risk-free return requires that the holdings of all risky assets be grossed up.

88 The assumption of much of the economics profession, and the maintained hypothesis of a number of empirical studies of risk aversion, is that relative risk aversion is constant, with the empirical work devoted to estimating the coefficient. See, e.g., Raj Chetty, "A New Method of Estimating Risk Aversion," 86 Am. Econ. Review 1821 (2006); Louis Kaplow, "The Value of a Statistical Life and the Coefficient of Risk Aversion," 31 J. of Risk and Uncertainty 23 (2006); Pierre-Andre Chiaporri and Monica Paiella, "Relative Risk is Constant: Evid-ence from Panel Data," DES Discussion Paper No. 5 (University of Naples "Parthenope", 2008).

89 As a very crude guide, according to 2005 preliminary SOI data, capital gains and capital gain distributions (net of capital losses) reported on individual returns amounted to about $\$ 618$ billion, representing approximately 8.2 percent of 2005 individual income (net of loss). Wages and salaries accounted for about 69.5 percent of individual income, and capital gains accounted for about 27 percent of all non wage and salary income. 
things it is not doing so by much to say that propositions such as that an income tax "collect[s] ... tax on the risk free return and only that tax," 90 and "that the difference between income and consumption taxes is the treatment of the risk free" return, ${ }^{91}$ have been reified in the literature, to the point of overshadowing that, at least in nominal terms, substantial income is reported from what are usually thought to be risk-bearing activities, a fact that is mostly ignored, as though it were some sort of fiscal mirage.

In most instances the mere exegesis of the examples is taken as settling the matter, while in others it has been argued that one may simply infer from observed behavior that economic actors have in fact adjusted to taxation by grossing up their holdings of risky assets. What I wish to underscore here is that, stated or not, such inferences are unwarranted. In the presence of ambiguous theoretical predictions about what economic actors optimally do, and the absence of empirical grounds for believing that constant absolute risk aversion is a good account of individual risk tolerance, one cannot simply sit back and say that, whatever the data might suggest, all that we are getting with the income tax is a tax on the risk free return, just because a couple of lines of algebra suggest that we might think of it that way. While some conjectures are more plausible than others, observed taxpayer conduct could in principle map back to almost any imaginable behavior in the (admittedly hypothetical) world without tax. We are not now in a position to say, theoretically or empirically, what observed behavior actually would have translated into in that world. Absent that ability, given the prevailing methodology, ${ }^{92}$ we are not yet in position to characterize in a qualitative way what might reasonably be inferred about conduct in a pre-tax world just from the taxable income and tax liabilities we actually observe. Without the conceptual foundation furnished by Warren's original argument (and its implicit assumptions about taxpayer behavior) it is far from clear that we are justified in thinking of the nominal taxes as just some sort of (zero net present value) ${ }^{93}$ fee paid to avoid the taxation of returns from risky investments, rather than more simply as tax on the risky returns themselves.

In such circumstances circumspection suggests that we continue to take seriously the probable, practical differences between income and cash-flow taxation, and indeed the differences

\footnotetext{
90 E.g., Weisbach, supra note 3, at 18.

91 E.g., Bradford, supra note 4, at 224 \& n. 4.

92 See supra, text preceding note 15.

93 See Gentry \& Hubbard, supra note 4, at 7.
} 
between an income tax and a tax on the riskless return. Even if we knew that investors would under an income tax gross-up their pre-tax holdings of risky assets, or (what is not the same thing) that under a tax on the riskless return they would scale-down their holdings of risky assets, ${ }^{94}$ those systems would produce very different revenues for the government, as a simple comparison of Examples 1, 2, 3, and 3A alone would suggest. But one period examples can be misleading, ${ }^{95}$ so it is useful to consider how they would look with a (modestly) extended horizon, for purposes of comparing both the final position of the investor and of the taxes her conduct would produce. The results of one such exercise are arrayed in Table I, which compares final period outcomes for the investor, and the present value of the taxes she pays, assuming her portfolio from Examples 0 and 3 continued for five years, under five different regimes: a cashflow tax, a conventional income tax with no portfolio adjustments, an accrual-based income tax with portfolio adjustments, a realization-based tax with adjustments, and a tax on the riskless return. From the possible assumptions about taxpayer conduct when adjustments are made we use that most consistent with the prevailing conventional wisdom, that the investor exhibits constant absolute risk aversion: under either conventional income tax with adjustments she exactly grosses-up her holding of the risky asset; under the risk free return only tax she adheres to her original portfolio allocation; under a cash-flow tax she grosses up both. ${ }^{96}$

94 See supra, text and notes at notes 32-33.

95 While those tables suggest that tax liabilities would be higher under an income tax with the portfolio adjusted (Example 3) than with no adjustment (Example 1) or under a tax on the riskless return (Example 3A), they also suggest that tax on investment returns under the cash-flow tax (Example 2) are highest, but only on an undiscounted basis, as discounting is not accounted for in those one period examples.

96 Consistency with this assumption requires that, in rebalancing her portfolio at the beginning of each year, the taxpayer allocate all earnings from the prior year to the riskless asset, so that $\$ 71.43$ is invested in the risky asset at the beginning of each year under each regime other the than the risk-free return only tax; under the latter $\$ 50$ is invested in the risky asset at the beginning of each year. See supra note 43. 
TABLE I

\begin{tabular}{|c|c|c|c|}
\hline $\begin{array}{c}\text { Assumptions: } \\
\text { W }_{0}=\$ 100 \\
\mathrm{r}=0.02 \\
\mathrm{R}=0.08 \\
\mathrm{t}=0.30 \\
\alpha=0.50\end{array}$ & \multicolumn{3}{|c|}{ 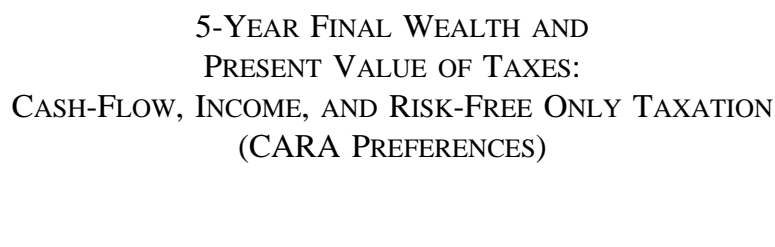 } \\
\hline $\operatorname{Tax}$ & Wealth $_{T}:$ & PV Tax: & $D R^{97}:$ \\
\hline Cash-Flow: Full Gross-up & 126.02 & 42.32 & PT \\
\hline Realization: No Adjustment & 120.07 & 50.09 & AT \\
\hline Accrual: Gross-up & 122.62 & 51.38 & AT \\
\hline Realization: Gross-up & 122.90 & 50.77 & AT \\
\hline Risk Free Only: Adjustment ${ }^{98}$ & 122.62 & 45.80 & AT \\
\hline
\end{tabular}

Note, first, as one would expect, that the after-tax outcomes for the investor are broadly similar under each version of the income tax and, as predicted, identical under the accrual tax and the tax on the risk free return. As suggested by Example 1, the investor does worse under a conventional income tax with no adjustment than under either version with an adjustment. But the improvement under the latter, as Example 3 suggests, comes about as the result of higher expected returns from more risky portfolios, which also produce higher expected tax payments, even when reduced to present value. As one would also expect, the investor does slightly better under a realization-based than under an accrual version of an income tax, and very much better under the cash-flow tax than under any version of the income tax. When reduced to present value, moreover, the taxes under the cash-flow tax are lower than under any conventional version of an income tax. ${ }^{99}$ That should at least serve as a reminder that, stripped of its algebraic recon-

97 The cash flow taxes were discounted at the pre-tax portfolio rate of return ( 5 percent). All others taxes were discounted at an after-tax portfolio rate of return taken to be 3.5 percent for the income tax with no adjustment, and 4.4 percent in the other three cases. Given the reallocation of the conventional income tax portfolios that is the initial pre-tax rate of return (just under 6.3 percent), reduced by tax at 30 percent (to 4.4 percent). For the riskless return (50-50) portfolio, the pre-tax return is (initially) 5 percent, from which has been subtracted tax on the riskless return $(\$ 0.60)$ to produce an after tax rate of return of 4.4 percent. It is to be noted that with the rebalancing treatment required by the assumption of constant absolute risk aversion, the portfolio rates of return varied slightly over time with changing portfolio composition. The outcomes were quite insensitive to the implied variations in the discount rate, and they have been ignored.

98 The only portfolio adjustment under the risk-free return only tax was that required to keep the holding of the risky asset constant at $\$ 50$.

99 The present value of the cash-flow tax liabilities in this example is 18 percent less than the conventional income tax liabilities. That is partly attributable to the use of a pre-tax rate in discounting the cash-flow tax 
ceptualization, the conventional income tax, at a given rate, is almost certain to produce revenue from taxing capital income (however characterized) with a higher present value than will be produced by a cash-flow tax, and that the difference will be more pronounced on the assumption that the taxpayer adjusts her holding of risky assets in response to the tax.

Of interest also is a comparison of the revenues under the income tax and its risk free return only "equivalent." As already noted the latter produces the same after-tax outcome for the investor as the accrual version of the conventional tax. It produces taxes, however, whose present is 12 percent less than those produced by either version of the income tax, and are closer in present value to those produced by the cash-flow tax. That should serve notice that, for all the talk of the "equivalence" of a conventional income tax and a tax on the risk free return from the standpoint of the investor, the two are typically not equivalent for the government. It is true that if the government were to take up for its own account the risky assets that the investor sold in reducing her portfolio's pre-tax exposure, the overall outcome might then be equivalent. ${ }^{100}$ But that is not generally consistent with observed government behavior. ${ }^{101}$ Nor is it obvious that a world in which the government taxed only the risk free return and produced additional revenue by investing for its own account would be superior to one in which the government contented itself with a conventional income tax instead. Reservations about large-scale government participation in equity markets aside, such studies as there have been of wealth as an alternative to income taxation do not inspire confidence that a tax on the (imputed) riskless return, or some other form

liabilities, consistent with its effectively conferring an exemption. Even using an after-tax discount rate the cashflow tax liabilities would have a present value of $\$ 45.47$, still 12 percent less than the income tax liabilities.

100 Kaplow (1994), supra note 3, at 793.

101 E.g., James Banks \& Peter Diamond, The Base for Direct Taxation 46-48 (London, Institute for Fiscal Studies, 2008). [Perhaps mention SS financing episode; note also that it would be ironic to shift to a wealth tax, for all the concern with the impact of income taxes on risk; wealth tax might produce less risk taking than an income tax; absence of loss offsets?] 
of broad-based wealth tax, ${ }^{102}$ would prove easier to administer or less problem beset than even the problem beset income tax that we have.

But to return to the central point of this paper, even if a tax on the riskless return is in some illuminating sense equivalent to a conventional income tax, that does not serve to distinguish either of those two from a cash-flow tax (or other versions of a consumption tax). In the presence of a positive interest rate that relationship holds only if economic actors systematically exhibit constant absolute aversion to risk, and seek above all to replicate in a taxable world the portfolio risk they were assumed to have chosen in a world without tax. That is not an especially plausible account of economic conduct. With the more realistic assumptions of constant relative and decreasing absolute aversion to risk, the predicted response to imposition of an income tax would be to settle on reduced levels of after-tax risk, and lower expected after-tax returns, than if the investor had completely grossed-up. In quantitative terms that implies that the after-tax outcome will be more onerous than as if the investor had initially been taxed only on the risk free return. More importantly, it undermines the conceptual foundation for the qualitative claim that the incidence of an income tax on risky investments, and hence the difference between income and cash flow taxation, is tantamount to a tax on the risk free return. If in response to an income tax investors behave differently than simply grossing up, the algebraic basis for that claim disappears. Even without it, it remains the case, as the economics literature has had it since Domar \& Musgrave, that taxpayers typically will adjust to an income tax by increasing their pre-tax holdings of risky assets and their pre-tax expected returns, and will end up with better expected outcomes than if they had made no adjustment at all. Whether we think of the additional taxes such adjustments produce as just that, or as part of a process that has the effect of moderating the

102 Schenk, supra note 3, takes the position that a wealth tax would be preferred. It is to be noted, however, that she starts from the premise that it is "impossible to design an income tax that would . . . impose a burden on the return to risk," and then proceeds to outline a low rate wealth tax whose conceptual feasibility appears to depend on internally inconsistent assumptions. Her illustration involves an investor whose optimal choice in a no tax world is assumed to be a 50-50 allocation, and whose optimal choice under an income tax is assumed to be a grossed up holding of the pre-tax allocation to the risky asset (essentially identical to Examples 0 and 3 in Part I above). But in subsequent periods she again assumes that the investor's preferences are captured by an equal allocation of her pre-tax portfolio, when the implicit assumption of constant absolute risk aversion requires maintenance of her original investment in the risky asset, not recurring 50-50 allocations. Id. at 427, 437-440 \& $\mathrm{n}$. 66. It is not clear that the point of the illustration can be preserved after the substitution of assumptions about the investor's behavior that are consistent with Schenk's explicit belief that investors do gross-up, her conviction about the infeasibility of an income tax on risk, and the requirement implicit in those convictions (at least absent a zero risk free interest rate, which Schenk does not assume) that investors must systematically exhibit constant absolute aversion to risk. 
impact of an income tax on risk, neither realistically justifies the new conventional wisdom, that returns to risk are exempt from the income tax, that the income tax is indistinguishable from a tax on the risk free return, and, most importantly, that the only thing that distinguishes income from cash-flow taxation is tax on the risk free return. 



\section{APPENDIX}

Given a vector of assets with returns $R^{\mathrm{T}}=\left\{r_{1}, \ldots, r_{n}\right\}$ and portfolio coefficients $A^{\mathrm{T}}=\left\{\alpha_{1}, \ldots, \alpha_{\mathrm{n}}\right\}$ (with $\alpha_{\mathrm{i}} \geq 0$, all $i$, and $\sum_{\mathrm{i}} \alpha_{\mathrm{i}}=1$ ), define the return to the portfolio $A^{\mathrm{T}} R$ by

$$
\begin{gathered}
\Omega_{\alpha} \equiv \sum_{j=1}^{n} \alpha_{j}\left(1+r_{j}\right)=1+\sum_{j=1}^{n} \alpha_{j} r_{j} \\
=1+A^{T} R .
\end{gathered}
$$

Now enlarge, say, the $i$ th coefficient $\alpha_{i}$ to $\hat{\alpha}_{i} \equiv \alpha_{i} /(1-t)$, and rescale the remaining weights proportionately, defining $\hat{\alpha}_{j}(j \neq i)$ by

$$
\hat{\alpha}_{j} \equiv\left(1-\frac{\alpha_{i}}{1-t}\right)\left(\sum_{j \neq i} \alpha_{j}\right)^{-1} \alpha_{j}=\frac{1-t-\alpha_{i}}{(1-t)\left(1-\alpha_{i}\right)} \alpha_{j}
$$

(using $\sum_{\mathrm{j} \neq \mathrm{i}} \alpha_{\mathrm{j}}=1-\alpha_{\mathrm{i}}$ ). Note that the $\hat{\alpha}_{\mathrm{j}}$ are convex:

$$
\begin{gathered}
\sum_{j} \hat{\alpha}_{j}=\frac{\alpha_{i}}{1-t}+\frac{1-t-\alpha_{i}}{(1-t)\left(1-\alpha_{i}\right)} \sum_{j \neq i} \alpha_{j} \\
=\frac{\alpha_{i}}{1-t}+\frac{\left(1-t-\alpha_{i}\right)\left(1-\alpha_{i}\right)}{(1-t)\left(1-\alpha_{i}\right)}=\frac{\alpha_{i}}{1-t}+\frac{\left(1-t-\alpha_{i}\right)}{1-t}=1 .
\end{gathered}
$$

Now let $\hat{A}^{\mathrm{T}}=\left\{\hat{\alpha}_{1}, \ldots, \hat{\alpha}_{\mathrm{n}}\right\}$, and impose tax at rate $\mathrm{t}$ on $\hat{A}^{\mathrm{T}} R$ to get

$$
\begin{aligned}
1+\hat{A}^{T} R(1-t)= & 1+\frac{\alpha_{i} r_{i}}{1-t}(1-t)+\frac{1-t-\alpha_{i}}{(1-t)\left(1-\alpha_{i}\right)} \sum_{j \neq i} \alpha_{j} r_{j}(1-t) \\
= & 1+\sum_{j} \alpha_{j} r_{j}-\frac{t}{1-\alpha_{i}} \sum_{j \neq i} \alpha_{j} r_{j} \\
& =\Omega_{\alpha}-\frac{t}{1-\alpha_{i}} \sum_{j \neq i} \alpha_{j} r_{j} .
\end{aligned}
$$

The second term of (2) says that the portfolio is taxed on the weighted average return from all assets other than the $i$ th, with their weights normalized to one, so as though the weighted average return was earned across the entire portfolio. (Note, however, that the second term could also be interpreted as taxing the un-normalized weighted average return from those assets, at a tax rate that has been enlarged so as to span the entire portfolio, with the tax rate on the $i$ th asset impliedly set to 0 .)

It is straightforward that if (for example) the weights on both the $i$ th and $j$ th assets are enlarged in the same way, then for $k \neq i, j$, expression (1) becomes

$$
\hat{\alpha}_{k}=\frac{1-t-\alpha_{i}-\alpha_{j}}{(1-t)\left(1-\alpha_{i}-\alpha_{j}\right)} \alpha_{k},
$$

and (2) holds in a natural way.

Generally, if we enlarge $\alpha_{i}$ to $\hat{\alpha}_{i}=\alpha_{i} /(1-t)$ for $i<k$, then for $j=k, \ldots, n,(1)$ becomes 


$$
\hat{\alpha}_{j}=\frac{1-t-\sum_{i<k} \alpha_{i}}{(1-t)\left(1-\sum_{i<k} \alpha_{i}\right)} \alpha_{j}
$$

while (2) becomes

$$
\begin{gathered}
1+\sum_{i<k} \frac{\alpha_{i} r_{i}}{1-t}(1-t)+\frac{1-t-\sum_{i<k} \alpha_{j}}{(1-t)\left(1-\sum_{i<k} \alpha_{j}\right)} \sum_{j=k}^{n} \alpha_{j} r_{j}(1-t) \\
=1+\sum_{j} \alpha_{j} r_{j}-\frac{t}{1-\sum_{i<k} \alpha_{i}} \sum_{j=k}^{n} \alpha_{j} r_{j} \\
=\Omega_{\alpha}-\frac{t}{1-\sum_{i<k} \alpha_{i}} \sum_{j=k}^{n} \alpha_{j} r_{j},
\end{gathered}
$$

and the entire portfolio is again taxed on the weighted average of the returns $\left\{r_{k}, \ldots, r_{n}\right\}$, with the sum of the weights again normalized to one.

Applying ( $\left(1^{\prime \prime}\right)$ and (2") to the case in which the return on the $n$th asset is risk free and the holdings of all others are grossed up, yields $\hat{\alpha}_{\mathrm{i}}=\alpha_{\mathrm{i}} /(1-\mathrm{t})$ for $i<n$,

$$
\hat{\alpha}_{n}=\frac{1-t-\sum_{i<n} \alpha_{i}}{(1-t)\left(1-\sum_{i<n} \alpha_{i}\right)} \alpha_{n}=\frac{1-t-\left(1-\alpha_{n}\right)}{(1-t)\left(1-1+\alpha_{n}\right)} \alpha_{n}=\frac{\alpha_{n}-t}{(1-t)},
$$

and

$$
\begin{gathered}
1+\hat{A}^{T} R(1-t)=1+\sum_{j} a_{j} r_{j}-r_{n} t \\
=\Omega_{\alpha}-r_{n} t
\end{gathered}
$$

Here, then, just as in the two asset case, the return on the risk free asset is taxed as though earned on the entire portfolio, while the returns to the other assets appear to be effectively untaxed. 